\title{
THE EFFECTS OF KINESIOLOGY TAPE ON STATIC POSTURAL CONTROL IN INDIVIDUALS WITH FUNCTIONAL ANKLE INSTABILITY
}

\author{
KIEN TRUNG LY, B.H.Sc.
}

\author{
Thesis submitted to the University of Ottawa \\ in partial Fulfillment of the requirements for the \\ Masters of Science in Human Kinetics
}

School of Human Kinetics

Faculty of Health Sciences

University of Ottawa

(C) Kien Trung Ly, Ottawa, Canada, 2020 


\begin{abstract}
Functional ankle instability (FAI) is characterized by the recurrent giving way of the ankle and the constant feeling of instability that affects the quality of life of its patients adversely. Kinesiology Tape (KT), differed from the traditional rigid athletic tape, becomes more popular as a new therapeutic tool for injuries management. It is reported to decrease pain, promote blood circulation and natural healing of muscular functioning. However, scientific evidence of KT's effects on FAI remains very limited. Therefore, the purpose of the present study was to investigate if applying KT on the unstable ankle may improve static postural control in individuals with FAI. Twenty young adults with FAI performed a series of static quiet bipedal and unipedal stances on a force platform. Postural control was assessed by four measures derived from the centre of pressure (COP) data: 95\% Confidence ellipse of total displacements (area), standard deviation of displacements (SD), mean velocity and mean power frequency (MPF). Measurements were taken at three different times: baseline or no tape, immediately after the application of KT on the unstable ankle, and 24 hours after the taping application with the tape remaining on the ankle. Results revealed only minor changes in mean velocity and MPF in unipedal stances immediately after KT application. However, the overall results indicated statistically insignificant improvements in postural control performance neither immediately after KT application nor after 24 hours. In conclusion, our results suggest that the use of KT did not affect bipedal and unipedal stances of individuals with functional ankle instability.
\end{abstract}

Keywords: Static postural control, Bipedal stance, Unipedal stance, Kinesiology tape, Functional ankle instability 


\section{ACKNOWLEDGEMENTS}

First, I would like to thank my supervisor, Dr. Yves Lajoie, for his mentorship and guidance through the completion of my Master's thesis. You have made my last two years an incredible learning experience. Your support and teachings helped me develop the crucial knowledge in the field, the techniques in research, and, most importantly, the desire to learn more every day. I thank you for trusting me and accepting as your Master's student and giving me the opportunity to learn from you. I would also like to thank Dr. Nicole Paquet and Dr. Sarah Fraser for their contributions as members of my thesis committee. With your excellent knowledge, you have helped me improve my research protocols, therefore making my work completer and more valuable to the current literature.

A big thank you to Lucas Michaud for your invaluable help with data collection and your insights on the writing of my thesis. Thank you for being a great friend and an even better colleague.

Another thank you goes to my other lab mates. It was my great honour to share the lab with you, and I have learnt a lot from you for the last two years. Also, thank you all of my friends who have been with me through all my ups and downs during my journey.

To my parents, who love me unconditionally and have shaped me to the person I am today and to my dear sister, thank you so much for your advice and constant support. Finally, to my lovely girlfriend, you are a great inspiration for me. You have always believed in me and encouraged me never to give up. For that, I thank you from the very bottom of my heart, and I could not have done it without you! 


\section{TABLE OF CONTENTS}

LIST OF ABBREVIATIONS V V V

CHAPTER ONE: LITERATURE REVIEW 1

1.1 Postural Control 1

1.2 Ankle sprain and Functional ankle instability (FAI) 4

1.3 Methods of treatment and prevention of ankle sprain and FAI $\quad 7$

1.4 Unclear role of Kinesiology Tape (KT) in the treatment and prevention 9 of ankle sprain and FAI

$\begin{array}{ll}\text { CHAPTER TWO: INTRODUCTION } & 13\end{array}$

2.1 Introduction 13

2.2 Objective 16

2.3 Hypotheses 16

$\begin{array}{ll}\text { CHAPTER THREE: MANUSCRIPT } & 18\end{array}$

$\begin{array}{ll}\text { CHAPTER FOUR: GENERAL DISCUSSION } & 47\end{array}$

4.1 Effects of KT application on postural control in all standing tasks $\quad 47$

4.1.1 Postural control in bipedal stance versus in unipedal stance 48

4.2 Effects of KT application on postural control in unipedal stances $\quad 50$

4.2.1 Injured leg versus uninjured leg $\quad 50$

4.2.2 Effects of KT on mean velocity and MPF 51

4.2.3 Immediate or delayed effects or else?

CHAPTER FIVE: CONCLUSION

5.1 Summary of findings $\quad 54$

5.2 Limitations $\quad 55$

$\begin{array}{ll}\text { REFERENCES } & 57\end{array}$

$\begin{array}{ll}\text { APPENDIXES } & 71\end{array}$ 


\section{LIST OF ABBREVIATIONS}

CNS - Central nervous system

FAI - Functional ankle instability

KT - Kinesiology Tape

$\mathrm{COM}$ - Center of mass

COG - Center of gravity

$\mathrm{COP}-$ Center of pressure

Area - Area of $95 \%$ confidence ellipse

SD - Standard deviation of COP

Mean velocity - Mean velocity of COP

MPF - Mean power frequency of COP

AP - Anteroposterior

ML - Mediolateral

ANOVA - Analysis of variance

SEBT - Star excursion balance test

EMG - Electromyography

ROM - Range of motion 


\section{CHAPTER ONE: REVIEW OF LITERATURE}

\subsection{Postural Control}

In everyday living, our human body performs postural control all the time with or without our consciousness. According to Shumway Cook and Woollacott (1995), postural control consists of controlling the position of the body in space to allow two things: orientation and equilibrium. The equilibrium is the ability to maintain the proper alignment of different body segments against destabilizing gravitational forces acting on them. The postural orientation is the ability to stay stable during a movement, and the postural equilibrium is the ability to maintain stability while standing (Horak, 2006). Three major sensory systems, including vision, somatosensory and vestibular system, are involved heavily in the regulation of posture and equilibrium. The somatosensory system is a complex system of different sensors, including proprioceptive, cutaneous, and joint. It senses the position and velocity of all body segments and responds to changes at the surface or inside the body (Winter, 1995). Vision is involved in the planning of our locomotion. In conjunction with the somatosensory system, it also provides information about the orientation of the body and head concerning the external environment (Winter et al., 1998). Finally, the vestibular system is sensitive to linear and angular accelerations of the head in space. It acts as extremely precise guidelines for spatial orientation and provides direct feedback to the postural muscles (Peterka, 2002). These systems work together to create an internal frame of reference of the human body in the environment. Then, the central nervous system (CNS) employs this internal representation of the human body to ensure the postural stability by making correction movements at the ankle and hip level through the muscular synergies (Samuel, Solomon, \& Mohan, 2015; Paillard, 2016). 
Each stationary object has a center of mass (COM), which is a mean position of all the segments in a body or a system and a center of gravity (COG), which is a vertical projection of COM on the ground (Winter, 1995). According to Pollock et al. (2000), the static balance was defined as the state of an object when the resultant forces acting upon it is zero. But for static human balance, the goal is to make sure that the COG is always staying within the base of support (BOS) (Carpenter, Murnaghan, \& Inglis, 2010). To achieve this goal, while standing, our body uses the ankles as the primary strategy in which the body acts as an inverted pendulum at the ankles level using plantarflexion/dorsiflexion mechanisms of our feet to create stiffness as postural correction movements (Winter et al., 1998; Friel, McLean, Myers, \& Caceres, 2006). These movements will cause the displacements of the center of pressure (COP), which represents a weighted average of all the pressures over the surface of the area in contact with the ground or the net ground reaction force vector. It is independent of COG. Notably, our body is continuously swaying in anteroposterior and mediolateral directions as the results of the delay of those correction movements (Winter et al., 2001). According to research, an increase in postural sway is commonly associated with postural instability (Stins \& Beek, 2012), while decreases in postural sway shows a better postural control and a healthier state of the human body (Paillard \& Noé, 2015).

When a person stands quietly on a single force platform, the researchers evaluate his or her postural control by studying the movements of the COP over time. The position of COP depends on the stance of the person. For example: in an unipedal stance (i.e. standing on one leg), the COP lies within the standing foot. However, the COP lies somewhere between the two feet, depending on the relative weight taken by each foot in a bipedal stance (i.e. standing on two feet) (Winter, 1995). Various parameters derived from COP give different types of information 
on postural control mechanisms. The sway area describes displacements of COP; the mean velocity of COP reflects the speed of postural regulation movements; the standard deviation represents the variability of COP's displacements; the mean power frequency of COP suggests a level of stiffness around the ankles which is the sensorimotor integration as a result of activation of degrees of freedom and coherence between reflexive and voluntary movement (cocontraction) of the muscles at the ankle level (Winter et al., 1997; Carpenter et al., 2001; Wulf, McNevin \& Shea, 2001; McNevin et al., 2003).

Researchers have applied a static balance paradigm (i.e. performing different quiet stances) as a postural control evaluation method in their studies. Among static balance tasks, bipedal and unipedal stances are proven to have excellent test-retest reliability (Paillard \& Noé, 2015). Compared to the unipedal stance, in the domain of postural control, the bipedal stance, as a safe balance task, has been of greater interest from researchers. Research showed that a person in a bipedal stance has a larger BOS than in an unipedal stance. This characteristic offers the bipedal stance greater stability with a smaller sway area (Paillard \& Noé, 2015); more postural control's regulating movements happen in the anteroposterior (AP) direction (Richer et al., 2017).

In contrast, the unipedal stance, with a narrower BOS, is less stable and produces more movements in the ML direction to keep the human body balanced (Muehlbauer et al., 2014). Unipedal stance represents a challenging but feasible balance task (Springer et al., 2007), and postural control in this stance is crucial because it frequently occurs within many daily living and sports activities (e.g. walking, jumping, landing, etc.) Therefore, more studies have been done to understand better about this form of balance. Postural control during the unipedal stance followed a U-shaped relationship between the static balance performance and age (Kurz et al., 
2018): young adults had better postural control compared to children and older adults. This study also demonstrated that children used different strategies of muscular activation in the ankle area (i.e. higher activation of tibialis anterior) compared to the other two populations (i.e. coactivation of tibialis anterior and soleus in both young and older adults) to maintain their balance. Moreover, in the unipedal stance, young adults performed better or possessed a greater postural steadiness than older adults due to their ability to reduce ground reaction force variability (Jonsson, Seiger \& Hirschfeld, 2004).

Overall, despite the difference between the bipedal and unipedal stance, they are both highly reliable methods and contribute to a better understanding of human postural control. Results of static balance performance in both stances using different indicators (i.e. COP parameters, performance time, electromyography, etc.) could help detect differences between populations (i.e. young vs older adults; pathological vs healthy participants); to predict falling risks; and to evaluate the efficacy of training programs (Maki, Holliday et Topper, 1994; Chomiak et al., 2015; Kouvetioli et al. 2015; Laatar et al., 2018).

\subsection{Ankle Sprain and Functional Ankle Instability}

Knowing that our feet (Chiari, Rocchi and Capello, 2002) and ankle (Horak, 2006) play an essential role in human postural control, any physical damage to the feet or ankles will modify our posture. A lateral ankle sprain is one of the most common musculoskeletal injuries (Doherty et al., 2014) and sports-related injuries (Fong et al., 2007) that will affect the static and dynamic posture negatively. The authors (Freeman et al., 1965; Steinberg et al., 2018) concluded that an ankle sprain would damage articular structures and articular receptors at the ankle level. The severe consequences of an ankle sprain include ankle instability and sprain recurrences. Recurrence rates as high as $70 \%$ in patients suffering from an acute lateral ligament injury to the 
ankle have been reported (McKay et al., 2001). Stretched and torn ligaments or fractured bone are the consequences of the mechanical damage that may lead to mechanical ankle instability, which is a pathological laxity of the ankle joint that creates abnormal physical movements of the ankle joint (Hertel, 2002). It will produce hypermobility characterized by an excessive range of motion (ROM) in foot plantarflexion but limiting in foot dorsiflexion. That will lead to a higher chance of re-sprain ankle joint inversion. Contrarily, hypermobility of foot dorsiflexion and limited ROM of foot plantarflexion will increase eversion ankle sprain recurrence.

Compensatory movements of the surrounding joints will be made to restore normal physiological movements of the ankle. However, this compensating strategy will then create abnormal tension back to the ankle's articular receptors, thus can affect the joint's proprioceptive response (Soavi et al., 2000). According to Miklovic et al. (2017), without early rehabilitative intervention immediately following a lateral ankle sprain, it may eventually develop into ankle instability.

Functional ankle instability (FAI) is a category of ankle instability. It refers to frequent episodes of "giving way" of the ankle joint and the feeling of ankle instability (Hertel, 2002). The "giving way" is the regular occurrence of uncontrolled and unconscious excessive inversion of the foot without necessarily causing an acute ankle sprain (Delahunt, Coughlan et al., 2010). According to a meta-analysis in 2010 (Munn, Sullivan and Schneiders), this instability may occur due to many functional insufficiencies, usually after one or many untreated ankle sprains. First, human neuromuscular control relies on the afferent information from mechanoreceptors in joint structures and ligaments (Riemann \& Lephart, 2002). They are responsible for joint motion detection and position sense (Konradsen, 2002). Proper communication between the afferent and efferent input is essential to control precise physiological joint motion. For example: when making a step using the right foot on an even surface, cutaneous and mechanoreceptors in the 
foot and ankle area receive and send the information about the environment (i.e. surface to step on) to the central nervous system (CNS). Then, the CNS will control the movement of the muscles around this area (i.e. tibialis anterior, gastrocnemius, etc.) to adapt to the environment by efferent inputs to contract them to provide stability to the ankle to prevent rolling the ankle. Therefore, damage to mechanoreceptors following an ankle sprain may affect their ability to send proper afferent information, which further affects the neuromuscular activation of the ankle joint. Consequently, it will lead to significant deficits in neuromuscular control in the limb of the unstable ankle, which will result in longer peroneal reflex latency time and longer reaction time of tibialis anterior muscle (Hopkins et al., 2009; Ahn et al., 2011; Donahue et al., 2014) and in proprioception via joint position sense (Hertel, 2002; Refshauge, Kilbreath, \& Raymond, 2003) in participants with FAI when compared to the healthy leg and the control groups. Also, the ankle instability can also be a consequence of a significant decrease in the evertor muscle strength of the unstable ankle due to physical damage caused by ankle sprains (Konradsen, Olsen, \& Hansen, 1998).

The combination of altered neuromuscular control, proprioception and muscle strength may lead to a significant impairment in postural control because of FAI. Perrin et al. (1997) reported postural control deficits in professional national basketball players with a history of ankle instability compared to healthy controls. Similar results on postural control deficits were also confirmed in collegiate athletes with FAI using the Balance Error Scoring System (BESS) in a study of Docherty et al. (2006). The amplitude of lateral sway increased because the ankle is unable to maintain balance (Levangie \& Norkin, 2001). When the ankles could no longer correct postural control, our body would then rely on the hip strategy in which hip flexion or extension is performed in the direction of perturbation to regain postural stability (Tropp, Odenrick \& 
Gillquist, 1985). The hip strategy is detected by the activation of hip abductor muscles (Beckman and Buchanan, 1995) and is used as a compensation method (Hertel, 2002; Kazemi et al., 2017). However, a study in 2006 (Friel, McLean, Myers, \& Caceres) proved that the hip abductor got weaker steadily due to the effects of ankle injuries. These authors argue that the hip strategy will eventually become less efficient than the ankle strategy. Therefore, postural control will be affected adversely in the unstable ankle individuals. It has been found that participants with an unstable ankle had impairments in muscle activation not only at the ankle but also in the more proximal regions (i.e. quadriceps and gluteus medius muscles) (Van Deun et al., 2007), which may decrease their postural control ability to overcome the changes in the transition from bipedal stance to unipedal stance (Dingenen et al., 2013).

\subsection{Methods of treatment and prevention of ankle sprain and FAI}

Ankle sprain and FAI can result in high medical expenses for its diagnosis and treatment (Bielska et al., 2017). It will affect the quality of daily living activities in the general population, but in many cases, it might be the ending point of many athletes' careers. For example, English footballers' career is affected by ankle osteoarthritis and FAI due to chronic recurrence ankle sprains (Yeung et al., 1994; Turner, Barlow, \& Heathcote-Elliot, 2000; Kujit et al., 2012). Therefore, methods of treating and preventing these ankle problems are of great importance.

We know the basic R.I.C.E (rest, ice, compression and elevation) as the standard first aid for an acute ankle sprain. Then, taping or bracing act as the ankle stabilizers and are used to help the patients with functional aspects and locomotion. They support and immobilize the ankle joint for stability by limiting inversion and eversion of the foot, without compromising regular joint mechanics, and for preventing the sprain recurrence (Bot \& Mechelen, 1999). There is evidence that standard rigid athletic tape and ankle brace offer support to joint mechanical stability by 
restricting the range of motion to prevent sprain recurrence, help with proprioception and improve functional performance (Dizon \& Reyes, 2009; Kerkhoffs et al., 2012). Kuni et al. (2016) showed evidence that rigid tape and soft brace offer high stability of the midfoot region and maximum reduction of plantar flexion that will help to prevent ankle sprain recurrence in participants with ankle instability. Moreover, rigid athletic taping proved to offer therapeutic injury preventive effect in changing foot kinematics of unstable ankle participants during running (Deschamps et al., 2016), also during landing tests (De Ridder et al., 2020) which reduces the chance of ankle sprain's recurrence.

However, Cordova (2002) argued that the constriction to movement conferred by a rigid tape might disadvantage performance. Indeed, it is shown that rigid tape on the ankle created adverse effects on knee biomechanics of the participants who were semi-pro female basketball players doing basketball-specific tasks (Williams et al., 2018). One study by Raymond et al. (2012) concluded the use of athletic ankle tape or brace did not affect proprioceptive acuity in participants with chronic ankle instability. Also, Hopper et al. (2010) and Halim-Kertagenara et al. (2017) had assessed participants with FAI wearing rigid ankle taping. They observed no improvement in the performance in functional tests, including figure-8 hopping test, hopping obstacle course, star excursion balance test (SEBT), single-leg stance and stair descent test. Using Time-to-stabilization to evaluate dynamic postural stability in participants with FAI, Wikstrom et al. (2006) proved that semirigid and soft braces may help with the attenuation of vertical forces yet did not improve stability performance at all.

Other interventions including manual therapy (Doherty et al., 2017), operative treatment (Yasui et al., 2016), physical training program (Kim et al., 2014), gait training (Feger et al., 2017), and balance training with virtual reality (Kim \& Heo, 2015) might help with preventing 
an ankle sprain in FAI patients. Still, with a mix of scientific evidence, an efficient method to help with FAI is not yet to be determined. Interestingly, Elshemy et al. (2013) had investigated the effectiveness of the proprioceptive training program versus Kinesiology Tape. The authors suggested that both interventions were beneficial because of the improvements in the dynamic position sense of the ankle and the eversion to inversion strength ratios in children with FAI. However, they praised the training program over the Kinesiology Tape as it could be more regularly scheduled in the rehabilitation for those patients.

\subsection{Unclear role of Kinesiology Tape in the treatment and prevention of ankle sprain and} FAI

Nowadays, it is easier than ever to have access to the Kinesiology Tape (KT) as it is getting more global popularity in the treatment and prevention of injuries in many areas of the human body. It was first introduced in 1979 but had to wait until the 2008 Olympic Games for its excellent public exposure with the products from the exclusive sponsor Kinesio ${ }^{\mathrm{TM}}$. KT is marketed as an elastic tape, with its stretching capability to $140 \%$ of its length, offers numerous advantages to users: alleviates discomfort, promotes blood circulation, facilitates lymphatic drainage, provides support to injured muscles and joints, and accelerate the natural healing process. Plus, KT is made with sweat and water wicking technology and heat-activated adhesion that allows the tape to be worn for much longer than traditional white cloth tape, sometimes up to 3 to 5 days. KT is used to treat many disorders as shoulders pain, knee conditions, ankle sprain, patients with stroke etc., by reducing pain, promoting a joint range of motion, and regaining strength and proprioceptive acuity (Williams et al., 2012; Rojhani-Shirazi et al., 2015; Zahra et al., 2015). 
Nonetheless, there have been very few studies looking at the efficacy of KT on FAI despite knowing the detrimental effects of FAI on the quality of life of patients. A meta-analysis indicated that KT was superior to other taping methods on helping improve ankle functional performance (Wang et al., 2018). This meta-analysis reported studies that found KT could enhance proprioception in joint position sense (Seo et al., 2016) and force sense (Simon et al., 2014), dynamic balance in SEBT (Lee \& Lee, 2017), dynamic balance using the Sensory Organization Test (de-la-Torre-Domingo et al., 2015), and foot kinematics during gait (Yen et al., 2018). However, several studies found KT did not produce any significant effects (Bicici, Karatas \& Baltaci, 2012; Hettle et al., 2013; Shields et al., 2013; Bailey \& Firth, 2017).

These authors (Bicici et al., 2012; Hettle et al., 2013; Shields et al., 2013; Simon et al., 2014; Lee \& Lee, 2015; de-la-Torre-Domingo et al., 2015; Seo et al., 2016; Bailey \& Firth, 2017; Yen et al., 2018) had studied KT's effects on proprioception, dynamic balance tasks, and sports-specific tasks in participants with FAI. Most of these studies concluded there were no significant benefits to using KT. Only the results of Simon et al. (2014) and Lee and Lee (2015) suggested that KT might help with treating FAI and preventing ankle sprain. In this line of research, the static balance has been rarely examined even though it is a crucial component of human postural control. McGuine, Greene, Best, and Leverson (2000) found that the static unipedal stance test is reliable and valid for predicting ankle injury when using force plates to quantify postural sway. Similarly, according to Paillard and Noé (2015), the static bipedal stance has been evaluated as a reliable postural control test and has been used regularly in postural control research. Therefore, studying KT using static balance tasks could provide useful information on the effects of KT on postural control. 
Most of the studies on KT's role in treating FAI selected only varsity, semi-pro or professional athletes as their participants, i.e. university sports clubs' members (Hettle et al., 2013), footballers (Lee \& Lee, 2015; Bailey \& Firth, 2017) or basketball players (Bicici et al., 2012). However, there are very few that investigated the effects of KT on FAI with participants who represent the general or non-athlete population. Plus, other studies looked at KT's effects on healthy population and found no improvement in performance in participants as expected since there probably is no room for improvement in a healthy ankle (Halseth et al., 2004; Semple et al., 2012; Nakajima et al., 2013, Kuni et al., 2016). Hence, further research of KT on FAI patients from a general population or non-athlete is much needed.

Also, the evidence is still limited to how KT can be beneficial with its delayed effects in the domain of injury management, especially in treating FAI. Research in 2015 (Lee \& Lee) concluded the positive effects of KT in FAI patients by improving their performance in dynamic balance tasks. This study was able to determine the short-term effects of KT when their measurements took place immediately after the taping application. On the other hand, research by Simon et al. (2014) shed light on the long-term effects of KT when they found improvement in proprioception measured by force sense after 72 hours following the KT application. These authors found that there was a significant difference in proprioceptive movements when comparing immediately after taping to $72 \mathrm{hrs}$ later. Therefore, they argued that KT had delayed positive effects when participants wore it for an extended period. Also, another study (de-laTorre-Domingo et al., 2015) noticed the use of KT after seven days on FAI patients improve their balance measured by the Sensory Information Test on a computerized dynamic posturography device. However, these researchers discussed that participants' postural control improvements were due to KT's effects not only on physiological aspects but also on 
psychological aspects as participants may perceive more confidence, reassurance and stability in their posture when wearing the tape for seven days. Consequently, learning the effects of KT at a 24-hour or 48-hour period after the taping application might confirm whether KT has delayed impacts on the functional aspects, or it only induces psychological effects on the participants. 


\section{CHAPTER TWO: INTRODUCTION}

\section{$2.1 \quad$ Introduction}

Postural control is one of the essential functions of daily human life. According to Shumway Cook and Woollacott (1995), postural control consists of controlling the position of the body in space to allow two things: orientation and equilibrium. The equilibrium is the ability to maintain the proper alignment of different body segments against destabilizing gravitational forces acting on them. The postural orientation is the ability to stay stable during a movement, and the postural equilibrium is the ability to maintain stability while standing (Horak, 2006). Three major sensory systems, including proprioception, vision and vestibular system, work together to create an internal frame of reference of the human body in the environment. The central nervous system then employs this internal representation of the human body to ensure the postural stability by making correction movements at the ankles and hip level through the muscular synergies (Winter et al., 1998; Samuel, Solomon, \& Mohan, 2015; Paillard, 2016).

An ankle sprain is one of the most common musculoskeletal injuries (Doherty et al., 2014) and sports-related injuries (Fong et al., 2007). It might result in high medical expenses for the diagnosis, treatment, and rehabilitation programs. An ankle sprain damages articular structures and articular receptors at the ankle level. The severe consequences of an ankle sprain include ankle instability and sprain recurrences. Recurrence rates as high as $70 \%$ in patients suffering from an acute lateral ligament injury to the ankle have been reported (McKay et al., 2001).

Functional ankle instability (FAI) is a category of ankle instability. It refers to frequent episodes of "giving way" of the ankle joint and the feeling of ankle instability (Hertel, 2002). 
The "giving way" is the regular occurrence of uncontrolled and unconscious of excessive inversion of the foot without necessarily causing an acute ankle sprain (Delahunt, Coughlan et al., 2010). According to a meta-analysis in 2010 (Munn, Sullivan and Schneiders), this instability may occur due to many functional insufficiencies, usually after one or many untreated ankle sprains. It has been found that participants with unstable ankle had impairments in muscle activation not only at the ankle but also in the more proximal regions (i.e. quadriceps and gluteus medius muscles) (Van Deun et al., 2007), which may decrease their postural control ability to overcome the changes in the transition from bipedal stance to unipedal stance (Dingenen et al., 2013). The combination of altered neuromuscular control, proprioception and muscle strength may lead to a significant impairment in postural control because of FAI (Hertel, 2008). That will not only affect the quality of daily living activities in the general population but, in many cases, might be the ending point of many athletes' careers. Therefore, methods of treating and preventing ankle sprain and ankle instability are of great importance.

Substantial research in methods of treating and preventing ankle sprain and FAI has been done up to date, including athletic tape, sports braces, therapies, and training programs. However, no therapeutic approach has deemed to be the most efficient. Now, Kinesiology Tape (KT) is highly accessible and getting more global popularity as a new method of injury management. As being marketed, KT possesses a stretching capability to $140 \%$ of its length and can be worn up to 3-5 days. It is used to treat many disorders as shoulders pain, knee conditions, ankle sprain, patients with stroke etc., by reducing pain, promoting a joint range of motion, and regaining strength and proprioceptive acuity (Williams et al., 2012; Rojhani-Shirazi et al., 2015; Zahra et al., 2015). 
Nonetheless, the role of KT in treating ankle sprain and ankle instability remains unclear. The body of literature about the effects of KT on FAI is still limited. It is reported that KT improved performance in dynamic postural control (Lee and Lee, 2015) or proprioception (Simon et al., 2014) on participants with FAI, though, some studies have shown no significant effects at all (Bicici et al., 2012; Shields et al., 2013). Previous research focused heavily on athletes (Semple et al., 2012; Hettle, 2013; Bailey \& Firth, 2017), which leaves the role of KT still uncertain in the general population. Also, dynamic or sports-related tasks were performed dominantly in the research of using KT to treat FAI (Bicici et al., 2012; Lee \& Lee, 2015; Bailey \& Firth, 2017). Meanwhile, there are very few that studied on static postural control despite its importance in daily human activities (Paillard \& Noé, 2015).

These authors (McGuine et al., 2000; Paillard \& Noé, 2015) revealed that static balance tasks such as unipedal and bipedal stance are highly reliable and valid to evaluate postural control, despite their different characteristics (Jonsson, Seiger \& Hirschfeld, 2004; Muehlbauer et al., 2014; Richer et al., 2017; Kurz et al., 2018). When a person stands quietly on a single force platform, the researcher evaluates his or her postural control by studying the movements of the COP over time. Researchers have applied the static balance paradigm (i.e. performing quiet stances) as a postural control evaluation method in their studies. Their results of participants' performances (e.g. COP measurements, performance time, EMG, etc.) helped detect differences between populations (i.e. young vs old adults; pathological vs healthy participants), to predict falling risks, and to evaluate the efficacy of training programs (Maki, Holliday et Topper, 1994; Chomiak et al., 2015; Kouvetioli et al. 2015; Laatar et al., 2018). Therefore, studying KT using static balance tasks (i.e. bipedal and unipedal stances) could provide useful information on the effects of KT on postural control of individuals with FAI. 
There is limited scientific evidence on whether KT produces long-term benefits or not in the treatment of FAI, and whether KT needs a delay period before starting to affect its users or not. Previous studies found improvements in proprioception and dynamic postural control in their participants with FAI only in the immediate measurements after KT application to the unstable ankle (Lee \& Lee, 2015). On the other hand, in the same population, Simon et al. (2014) noticed a gain in proprioception when their participants had worn KT for 72 hours. Also, de-laTorre-Domingo et al. (2015) observed an improvement in the dynamic balance performance of their participants after having the KT application on their unstable ankle for seven days.

\subsection{Objective}

The purpose of this study is to quantify the effects of KT on postural control of individuals, who are from a general population (non-athletes), with functional ankle instability (FAI) in unipedal and bipedal stance when the taping is applied to the unstable ankle. This evaluation of postural control performance will help determine the role of KT in treating FAI in the general population.

\subsection{Hypotheses}

Based on the literature review performed, the immediate measurements after the application of Kinesiology Tape were essential and used in all studies about KT to evaluate the effects of the tape on individuals with unstable ankles. The method of Shields et al. (2013), who examined KT's effects on the performances of static unipedal stance of FAI individuals, showed that the measurements at 24 hours after the taping application were also an important indicator to evaluate the theory of KT's delayed effects on postural control. Therefore, for the present study, the first two hypotheses are: 
1) Kinesiology Tape application will improve postural control in both unipedal and bipedal stance in participants with FAI immediately after taping and 24 hours after taping with the tape remaining on the ankle.

2) Improvements in postural control will be greater 24 hours following the application of Kinesiology Tape on the FAI ankle compared to the results of testing immediately after taping.

Moreover, the literature showed that the individuals with FAI had their leg with the unstable ankle affected adversely by the deficits of mechanical structures, neuromuscular control, strength etc. Therefore, due to the possible differences between the injured leg and uninjured leg, the third hypothesis of this study is:

3) Postural control of the injured leg will be less stable than the uninjured leg in the unipedal stances. We expect only to see changes in the performance of the injured leg, which might indicate the effects of KT on the FAI ankle.

Finally, due to the different characteristics between the bipedal and unipedal stances that were mentioned earlier in the literature review, the fourth hypothesis predicted that:

4) Postural control in the bipedal stance will be different from the unipedal stances in sway directions. 


\section{CHAPTER THREE: MANUSCRIPT}

The effects of Kinesiology Tape on static postural control in individuals with Functional ankle instability

A version of this manuscript was submitted to the journal of Physical Therapy in Sport in May 2020 and is currently under review. 
The effects of Kinesiology Tape on static postural control in individuals with Functional ankle instability

Kien Ly ${ }^{1}$, Lucas Michaud ${ }^{1} \&$ Yves Lajoie $^{1}$

${ }^{1}$ School of Human Kinetics, University of Ottawa, ON, Canada 


\begin{abstract}
$\underline{\text { ABSTRACT }}$
Objective: To investigate if applying Kinesiology Tape (KT) on the unstable ankle may improve static postural control in individuals with Functional ankle instability.

Design: A repeated measured study. Participants performed a series of static quiet bipedal and unipedal stances on a force platform. Measurements were taken at three different times: baseline or no tape, immediately and 24 hours after the taping application with the tape remaining on the ankle.
\end{abstract}

Setting: A university's psychomotor laboratory.

Participants: Twenty young adults with Functional ankle instability aged from 18 to 30 years old. Outcome measures: Postural control was assessed by four measures derived from the centre of pressure data: Area of 95\% Confidence ellipse, standard deviation of displacements, mean velocity and mean power frequency. The analysis of variance (ANOVA) was performed to determine any significant improvement in postural control over time due to KT.

Results: Only minor changes in mean velocity and MPF in unipedal stances were observed immediately after KT application. However, the overall results indicated statistically insignificant improvements in postural control neither immediately after KT application nor after 24 hours.

Conclusion: Results suggest that the use of KT did not affect bipedal and unipedal stances of individuals with functional ankle instability. 
Keywords: Static postural control, Kinesiology tape, Functional ankle instability 


\section{Introduction}

A lateral ankle sprain is one of the most common musculoskeletal injuries (Doherty et al., 2017) and sports-related injuries (Fong et al., 2007), often requires high medical expenses for its diagnosis, treatment, and rehabilitation programs. The severe consequences of an ankle sprain include sprain recurrences and functional ankle instability (FAI), which refers to frequent episodes of "giving way" of the ankle joint and the feeling of ankle instability (Hertel, 2008). The "giving way" is the regular occurrence of uncontrolled and unconscious of excessive inversion of the foot without necessarily causing an acute ankle sprain (Delahunt, Coughlan et al., 2010). According to previous studies (Docherty, Valovich McLeod, \& Shultz, 2006; Hopkins et al., 2009; Munn, Sullivan, \& Schneiders, 2010), this instability in the FAI ankle may occur due to many functional insufficiencies and may lead to deficits in postural control. The impairments caused by FAI will not only affect the quality of daily living activities in the general population but, in many cases, might be the ending point of many athletes' careers. Therefore, methods of treating and preventing ankle sprain and FAI are of great importance.

KT has been gaining popularity throughout the world as a new method of intervention and prevention of musculoskeletal injuries. This elastic tape, as being marketed, made to stretch up to $140 \%$ of its length and to be worn up to 3 to 5 days, offers numerous advantages to users: alleviates pain and discomfort, provides support to injured muscles and joints, and accelerate the natural healing process. KT is used to treat many disorders like shoulders pain, knee conditions, ankle sprain, patients with stroke, etc., by reducing pain, promoting a joint range of motion, and regaining strength and proprioceptive acuity (Williams et al., 2012; Rojhani-Shirazi, Amirian \& Meftahi, 2015). 
However, there have been very few studies looking at the efficacy of KT on FAI despite knowing its detrimental effects on the quality of life of patients. A meta-analysis indicated that KT was superior to other taping methods on helping improve ankle functional performance (Wang et al., 2018). KT could enhance proprioception in joint position sense (Seo et al., 2016) and force sense (Simon, Garcia \& Docherty, 2014), dynamic balance in Star Excursion Balance Test (SEBT) (Lee \& Lee, 2017), dynamic balance using the Sensory Organization Test (de-laTorre-Domingo et al., 2015), and foot kinematics during gait (Yen et al., 2018). However, several studies found KT did not produce any significant effects (Bicici, Karatas \& Baltaci, 2012; Hettle et al., 2013; Shields et al., 2013; Bailey \& Firth, 2017).

Most of the research mentioned about FAI has been studying athletes in different sport-related or dynamic task settings. However, there are very few that investigated the effects of KT on FAI with participants who represent the general or non-athlete population. Plus, in this line of research, static balance has been rarely examined even though it plays a crucial component in human postural control. Previous research had established the reliability of the static unipedal stance to predict ankle injury via postural sway measures using the force platform (McGuine et al., 2000). The static bipedal stance is also highly reliable to learn about human postural control (Paillard and Noé, 2015). Therefore, studying KT using static balance tasks could provide useful information on the effects of KT on postural control.

Manufacturers of KT suggest to users that their products should be worn for a prolonged period of several days to benefit most of the delayed effects of KT. However, scientific research had not 
yet confirmed this theory. Previous study found improvements in proprioception and dynamic postural control in their participants with FAI only in the immediate measurements after KT application to the unstable ankle (Lee \& Lee, 2015). On the other hand, always with the ankle instability population, Simon et al. (2014) noticed a gain in proprioception when their participants had worn KT for 72 hours. Also, de-la-Torre-Domingo et al. (2015) observed an improvement in the dynamic balance performance of their participants after having the KT application on their unstable ankle for seven days.

The scarcity of literature exploring the role of $\mathrm{KT}$ in treating FAI is the fundamental reason for the present study. As KT is easily accessible and is marketed user-friendly for everyone, the objective of this study is to give further insights on the effects of KT on postural control in participants, who represent the general population, using static balance tasks. We hypothesized that Kinesiology Tape application on the unstable ankle of participants with FAI would improve their postural control in both unipedal and bipedal stance immediately after taping and 24 hours later with the tape remaining on the ankle. Moreover, we hypothesized that participants' postural control would be better after 24 hours following the application of KT compared to the immediate measurements. Due to functional deficits in the FAI ankle, with the application of KT, we hypothesized that postural control performance in the unipedal stance on the FAI ankle would have significant changes compared to the uninjured side. Finally, our last hypothesis predicted that postural control would be very different between bipedal and unipedal stances in terms of directions of oscillations. 


\section{Methods}

\subsection{Participants}

Twenty young adults with FAI (fourteen males and six females, $23.4 \pm 4.25$ years) participated in the study. All subjects filled out the Cumberland Ankle Instability Tool (CAIT), which established the criteria for classifying subjects with FAI (Hiller et al., 2006). Athletes of any levels or/and persons who do physical or sports-related activities for more than five hours per week couldn't partake in this study. The inclusion criteria included: previous lateral inversion ankle sprain on one leg only with swelling, pain, and temporary loss of function (but not in the prior three months), history of multiple episodes of the ankle giving way in the last six months, and a score of CAIT questionnaire below 27 points. The CAIT scores of our participants ranged from 11 to 25 points (mean: $18.6 \pm 4.26$ ). Participants were excluded if they reported a history of lower-limb injury other than unilateral ankle instability, previous non-specific extremity surgery, severe skin allergy to tape, any other problems that could affect their posture, and any involvement in any treatment for FAI in the past. Lastly, participants were asked for their dominant leg by answering which leg do they use to kick a soccer ball; eighteen were rightfooted, and two were left-footed. Five participants had an FAI ankle on their non-dominant leg.

All the participants provided written informed consent before participation, and the testing procedures used in the study were approved by the University's Research Ethics Board. On testing day, the participants were pain-free and were not involved in any physical activity. They could perform full weight bearing on both legs at the time of assessment. No requirements existed for specific physical activity levels among participants. 


\subsection{Apparatus}

An AMTI force platform (OR6-6-1000, Watertown, MA, USA) was used to record COP data at a sample rate of $500 \mathrm{~Hz}$.

SpiderTech $^{\mathrm{TM}}$ Therapeutic Kinesiology Tape was used in this study to assure the consistency of the material, shape, and length of the tape for application. Precisely, the Ankle Pre-cut Kinesiology Tape (gentle) for sensitive skin was applied to the FAI ankle of participants. This taping application of the Ankle Pre-cut KT followed the instructions of SpiderTech ${ }^{\mathrm{TM}}$ company (SpiderTech Inc., 2020) (Figure 1).

\subsection{Postural Tasks}

Participants performed all postural tasks quietly and barefooted on the force platform. They were asked to try to keep as stable as possible without voluntary movements of other parts of their body. For the bipedal stance, participants stood with their feet together. While in the unipedal stance, they stood either on their leg with FAI ankle or on their non-injured leg while having a 30 degrees knee flexion on their other leg (Shields et al., 2013). For both stances, arms were hanging loosely at the sides, and eyes were fixed on an eye-level target 3 meters ahead. The participants had to respect their foot placement showed by position markers on the force platform. Continuous observation of participants' foot placement by the researcher ensured standardization across trials. 


\subsection{Procedure}

Data were collected at three different measurement times: baseline/no tape (B), immediately after taping application (I), and 24 hours after taping with the tape remaining on the ankle (24h). Per measurement time, each participant performed three tasks in randomized order: unipedal stance on the leg with FAI ankle (C1), unipedal stance on the non-injured leg $(\mathrm{C} 2)$, and bipedal stance (C3). One familiarization trial was given for each task before data collection. The participant performed five trials per task for a total of 15 trials per measurement time. There was a two minutes break to ensure safety and wellbeing concerns before a participant moved onto the next task. Between the first and second day of the experiment, participants were asked to keep the taping intact as much as possible and to not engage in any physical activities other than their everyday activities.

Each trial started following a "GO" signal when participants reported being ready and lasted for 40 seconds. The first and last 5 seconds were discarded, leading to a 30 seconds interval for data analysis. That helped minimize the erroneous data made by participants' movements for not being stable yet or for knowing that the end of the trial was coming. This information was not disclosed to participants to not interfere with their performances. Also, at any time during the unipedal stance, the trial was discarded and was repeated if the non-stance leg touched down or the stance leg moved from its original placement on the force platform. Out of the total 900 trials from 20 participants, only nineteen trials were discarded then repeated. 


\subsection{Data analysis}

Four dependent variables were derived from the COP data using MATLAB software (MathWorks Inc., MA, USA) to assess postural control: area of 95\% confidence ellipse (area), standard deviation (SD) of COP in anteroposterior (AP) and mediolateral (ML) directions mean velocity of COP and mean power frequency (MPF) of COP in AP and ML directions. These variables that have been validated in previous research (Paillard \& Noé, 2015): area describes total displacements of COP; SD represents the variability of COP's displacements; mean velocity reflects the speed of postural regulation movements; MPF suggests a level of stiffness around the ankles which is the sensorimotor integration as a result of activation of degrees of freedom and coherence between reflexive and voluntary movement (co-contraction) of the muscles at ankle level. MPF was calculated following fast Fourier transformation (FFT) of the COP and COM signals. FFT estimates the power associated with frequency components contained within the signal, while MPF estimates the average frequency contained within a power spectrum (Winter et al., 1997). MPF was calculated following the formula: $M P F=\frac{\Sigma f \cdot P(f)}{\sum P(f)}$, Where f represents frequencies within the signal, and $\mathrm{P}$ is the power amplitude at each frequency.

\subsection{Statistical analysis}

All data are expressed in means with their respective standard deviation. A 3-way analysis of variance (ANOVA) with repeated measures on time (B, I, 24h), postural tasks $(\mathrm{C} 1, \mathrm{C} 2, \mathrm{C} 3)$, and sway directions (AP and ML) was performed for each dependent variable. To determine if KT had effects on the leg with FAI ankle compared to the uninjured leg without tape, another 3-way analysis of variance (ANOVA) with repeated measures on time (B, I, 24h), unipedal stance tasks 
(C1 and $\mathrm{C} 2$ ) and sway directions (AP and ML) was performed for each dependent variable. When Mauchly's Test of Sphericity was violated, Greenhouse-Geisser corrections were performed. Tukey HSD post-hoc test was performed to determine the location of significance when necessary. Statistical significance was set at $p<.05$.

\section{$3 \underline{\text { Results }}$}

Area of $95 \%$ Confidence Ellipse

Results revealed a significant main effect of tasks on area, $F(2,38)=78.6, p<.001, \eta^{2}{ }_{p}=0.81$. Area was significantly smaller in $\mathrm{C} 3$ than in $\mathrm{C} 1$ and $\mathrm{C} 2$. However, no significant difference was detected when comparing between two unipedal stances $\mathrm{C} 1$ and $\mathrm{C} 2$.

\section{[See Figure 2]}

\section{Standard Deviation of Centre of Pressure}

A significant main effect of postural tasks was found for SD of COP, $F(2,38)=90.6, p<.001$, $\eta^{2} \mathrm{p}=0.83$. Also, results reveal a significant main effect of sway directions, $F(1,19)=35.1 p<$ $.001, \eta_{\mathrm{p}}^{2}=0.65$. Post-hoc analysis of 2-way interaction between tasks and sway directions showed that in AP and ML direction, SD in C3 was significantly smaller compared to C1 and C2 $(p<.001)$

Between C1 and C2, only significant main effect of sway directions was found, $F(1,19)=63.1$, $p<.001, \eta_{\mathrm{p}}^{2}=0.77 . \mathrm{SD}$ in ML direction was significantly smaller than AP direction. 


\section{[See Figure 3]}

Mean Velocity of Centre of Pressure

Results revealed a significant main effect of tasks on mean velocity, $F(2,38)=102.1, p<.001$, $\eta_{p}^{2}=0.84$. Mean velocity in $\mathrm{C} 3$ was significantly smaller than $\mathrm{C} 1$ and $\mathrm{C} 2$.

Between $\mathrm{C} 1$ and $\mathrm{C} 2$, a significant main effect of time was found, $F(2,38)=3.28, p<.05, \eta^{2}{ }_{\mathrm{p}}=$ 0.15 . Post-hoc analysis revealed that mean velocity at time I was significantly smaller than at time B $(p<.05)$.

[See Figure 4]

Mean Power Frequency of Centre of Pressure

A significant main effect of postural tasks was found for MPF, $F(2,38)=67.8, p<.001, \eta^{2}{ }_{p}=$ 0.78. Also, results revealed a significant main effect of sway directions for MPF, $F(1,19)=64.8$, $p<.001, \eta_{\mathrm{p}}^{2}=0.77$. Post-hoc analysis of 2-way interaction between tasks and sway directions showed that in $\mathrm{AP}$ and ML direction, MPF in $\mathrm{C} 3$ was significantly smaller compared to $\mathrm{C} 1$ and $\mathrm{C} 2(p<.001)$.

[See Figure 5]

Between $\mathrm{C} 1$ and $\mathrm{C} 2$, a significant main effect of sway directions was found, $F(1,19)=114.1, p$ $<.001, \eta_{\mathrm{p}}^{2}=0.86$. MPF in ML was significantly higher than AP direction (Fig. 5). Also, there 
was a significant main effect of time, $F(2,38)=3.40, p<.05, \eta^{2} \mathrm{p}=0.15$. Post-hoc analysis revealed that MPF at time I was significantly smaller than at time B $(p<.05)$.

[See Figure 6]

\section{Discussion}

This study aimed to quantify the effects of Kinesiology Tape on postural control in generalpopulation individuals with FAI using a static balance tasks paradigm. It was hypothesized that the KT application would improve participants' postural control in both unipedal and bipedal stance immediately after taping and 24 hours after taping with the taping remaining on the ankle, and that postural control of these participants would continue to improve after 24 hours following the application of KT. Unfortunately, our results did not support the proposed hypotheses. Our results were not consistent with the body of literature demonstrating the improvements in postural control, which consist of a smaller area of COP and SD of COP, slower mean velocity, and higher MPF (Paillard \& Noé, 2015). The third hypothesis that predicted postural control in the unipedal stance on the FAI ankle would have significant changes compared to the uninjured side was also rejected. This, therefore, suggests that KT did not enhance postural control in individuals with FAI in a static quiet stance. As such, the role of KT in the intervention and prevention of FAI remains unclear.

The limited literature in general-population individuals with FAI showed that KT helped improving proprioception in force sense (Simon et al., 2014). Proprioception has been defined as the positional sense of the joint that plays a massive role in the static human balance (Winter et 
al., 2001). Therefore, KT might help with the proprioceptive deficits as one of the characters of FAI (Munn et al., 2010) to provide more stability. Consequently, it created the belief that the application of KT on the FAI ankle would promote a better postural control in static balance tasks. However, the present study's findings suggest that KT did not benefit postural control in FAI participants, as there were no significant improvements immediately after the taping application and 24 hours later. In all dependent variables, differences were only observed between postural tasks and directions of COP displacements. This could be explained as the bipedal stance was a completely different task from the unipedal stances, as we expected. A bipedal stance, with a broader base of support, offered more stability than an unipedal stance (Winter, 1995), which resulted in a smaller area (Fig. 2). Our $4^{\text {th }}$ hypothesis was confirmed: the unipedal stance produced more movements of the COP, especially in AP direction (Fig. 3) (Shiravi et al., 2017) and less stiffness with lower MPF in both directions (Fig. 5) when compared to the bipedal stance. Plus, no research had examined the transfer of balance ability from one standing task to the other. In other words, one could perform well in the bipedal stance but could do worse in the unipedal stance and vice versa. Moreover, no improvement in postural control due to KT in this study was in line with the results of de-la-Torre-Domingo et al. (2015). They found that KT did not enhance postural control of their participants in static bipedal stance tasks.

Hopkins et al. (2009) examined FAI participants and discovered deficits in peroneal latency and electromechanical delay in the participants' leg with an unstable ankle (the injured leg) compared to the uninjured leg. Consequently, we would have expected to see a more inadequate postural control in unipedal stance on the FAI leg compared to the injured side in the present 
study. However, our results did not show any significant differences between the two unipedal stances. Therefore, the $3^{\text {rd }}$ hypothesis was rejected. On the other hand, Sousa et al. (2017) indicated that the deficits in kinesthesia for the injured leg combined with the deficits in force sense for the uninjured leg could increase the risk of recurrence ankle injury in the FAI population. Therefore, this could explain why our results showed a similar postural control performance between two unipedal stances at baseline and why there could be room for improvements in both legs. That might have reflected in our results, which indicated that both $\mathrm{C} 1$ and $\mathrm{C} 2$ had led to changes in two variables. Precisely, mean velocity and MPF were significantly smaller at the immediate measurements compared to baseline (Fig. 4 \& 6).

Previous research concluded improvements of postural control were reflected by a slower speed of postural regulation movements (i.e. mean velocity) and an increase of the level of stiffness around the ankle (i.e. MPF) (Paillard \& Noé, 2015). This suggests that in this study, KT might have imposed a mixed of positive effect (i.e. a slower mean velocity) and negative effect (i.e. a decreased MPF) to the participants' postural control only at the immediate time after the taping application. A study in 2015 (Lee \& Lee) found immediate improvements in the performance of SEBT in their participants with FAI. Another study (Lee \& Lee, 2017) found a positive effect of KT on providing more stability to participants while testing different static postural tasks on different surfaces. In all postural conditions, the authors also measured the ankle's range of motion of participants before and after the taping application and obtained almost similar results. Both studies argued that KT, with its elastic property, may have helped postural control by enhancing the proprioception in the ankle area rather than by restricting the ankle joint structures. This phenomenon could be present in this study due to the design of the Ankle Pre-cut 
KT used in the taping procedure (Fig. 1), which allowed an even better range of motion of the ankle. Being marketed with therapeutic properties, the tape might have provided some tension relief and proprioceptive enhancement to the muscles around the unstable ankle, especially the peroneus longus and tibialis anterior who have essential roles in postural control but often show deficits in FAI patients (Ahn, Kim \& Kim, 2011; Donahue, Docherty \& Riley, 2014).

However, the immediate changes in mean velocity and MPF observed in this study did not support the theory of KT's delaying effects as being investigated in previous research. Similarly, Hettle et al. (2013) did not find any immediate effects of KT on their participants' unstable ankle using scores in the Star Excursion Balance Test as measurements. Moreover, Shields et al. (2013) did not notice relevant changes in their FAI participants' performance of the unipedal stance on the injured leg neither immediately after the KT application nor 24 hours later. However, another study on FAI individuals confirmed that wearing KT for 72 hours might have improved proprioceptive deficits in the unstable ankle area, reflected by a reduction of force sense errors (Simon et al., 2014). De-la-Torre-Domingo et al. (2015) pushed the limit even further when detecting improvements in their participants' dynamic balance only after seven days of having KT on the unstable ankle. Therefore, it was possible that theses immediate changes might have been the effects of adaptation. The participants could have got used to the difficulties of the postural tasks, especially the unipedal stances, after the trials of baseline. However, at the 24-hour mark, the fact that participants' performances on both legs did not differ from the baseline level nor the immediate measurements (Fig.6) rejected the long-term adaptation theory, also rejected our $3^{\text {rd }}$ hypothesis once more. Another possible explanation could relate to participants' perception of greater stability, confidence and reassurance when the 
tape was applied to the unstable ankle (Delahunt, McGrath et al., 2010). Consequently, participants in this study might have felt more confident immediately after the KT application, thus increasing their stability. Nonetheless, no measurements have been taken to support this claim.

The overall results showed no significant changes in postural control with the application of KT on the FAI ankle in the present study. This was somewhat similar to the findings of Shields et al. (2013). The authors found improvements only in two variables after the KT application. Yet, because of the very small size effects associated with these variables, no definite conclusion on the benefits of KT on postural control could be drawn. On the other hand, another study looking at FAI individuals confirmed that KT could help with the ankle's proprioception (Simon et al., 2014). A study of Elshemy and Battecha (2013) saw the positive effects of KT, when coupled with a therapeutic treatment program, on dynamic position sense of the ankle and eversion to inversion strength in young boys with FAI. However, the authors argued that the improvements might have been the results of the treatment program instead of the lone effects of KT. Therefore, with a mix of evidence, it remains unclear about the role of KT on human postural control by enhancing proprioception around the FAI ankle. As the present study did not look specifically at any change in proprioception at the ankle due to KT, it can neither be accepted nor rejected that KT may have these effects on the muscles and the ankle. Though, as this study demonstrated that KT did not lead to any meaningful improvements in the overall postural control measurements, all of the theoretical effects of KT warrant further investigation. 


\section{Conclusion}

In conclusion, the application of Kinesiology Tape to the unstable ankle produces no significant improvement to the static postural control of young individuals with FAI, both immediately and 24 hours after the taping application. However, the present study was the first one to focus on static postural control by utilizing pre-cut KT specialized for treating the ankle's injuries. Plus, with a lack of scientific evidence in the non-athlete population, this study contributed to a better understanding of the role of KT to human musculoskeletal injuries, especially the ankle sprain and FAI. Further research is much needed because the potential for Kinesiology Tape to play a part in the rehabilitation of FAI individuals could be crucial in the future for everyone, both athletes and non-athletes.

\section{$\underline{\text { References }}$}

Ahn, C. S., Kim, H. S., \& Kim, M. C. (2011). The Effect of the EMG Activity of the Lower Leg with Dynamic Balance of the Recreational Athletes with Functional Ankle Instability. Journal of Physical Therapy Science, 23(4), 579-583.

SpiderTech Inc. (2020). Ankle Pre-cut. https://spidertech.com/ankle

Bailey, D., \& Firth, P. (2017). Does kinesiology taping of the ankles affect proprioceptive control in professional football (soccer) players? Physical Therapy in Sport, 25, 94-98. 
Bicici, S., Karatas, N., \& Baltaci, G. (2012). Effect of athletic taping and kinesiotaping on measurements of functional performance in basketball players with chronic inversion ankle sprains, The International Journal of Sports Physical Therapy, 7(2),13.

Delahunt, E., Coughlan, G. F., Caulfield, B., Nightingale, E. J., Lin, C.-W. C., \& Hiller, C. E. (2010). Inclusion Criteria When Investigating Insufficiencies in Chronic Ankle Instability. Medicine \& Science in Sports \& Exercise, 42(11), 2106-2121.

Delahunt, E., McGrath, A., Doran, N., Coughlan, G.F. (2010). Effect of taping on actual and perceived dynamic postural stability in persons with chronic ankle instability. Archives of Physical Medicine and Rehabilitation, 91, 1383-1389.

de-la-Torre-Domingo, C., Alguacil-Diego, I. M., Molina-Rueda, F., López-Román, A., \& Fernández-Carnero, J. (2015). Effect of Kinesiology Tape on Measurements of Balance in Subjects With Chronic Ankle Instability: A Randomized Controlled Trial. Archives of Physical Medicine and Rehabilitation, 96(12), 2169-2175.

Doherty, C., Bleakley, C., Delahunt, E., \& Holden, S. (2017). Treatment and prevention of acute and recurrent ankle sprain: an overview of systematic reviews with meta-analysis. British Journal of Sports Medicine, 51(2), 113-125.

Docherty, C. L., Valovich McLeod, T. C., \& Shultz, S. J. (2006). Postural Control Deficits in Participants with Functional Ankle Instability as Measured by the Balance Error Scoring System: Clinical Journal of Sport Medicine, 16(3), 203-208.

Donahue, M. S., Docherty, C. L., \& Riley, Z. A. (2014). Decreased fibularis reflex response during inversion perturbations in FAI subjects. Journal of Electromyography and Kinesiology, 24(1), 84-89. 
Elshemy, S. A. \& Battecha, K. H. (2013). Kinesio Taping Versus Proprioceptive Training on Dynamic Position Sense of the Ankle and Eversion to Inversion Strength Ratios in Children with Functional Ankle Instability. Medical Journal of Cairo University, 81(2), 61-68.

Fong, D., Hong, Y., Chan, L. K., et al. (2007). A systematic review on ankle injury and ankle sprain in sports. Sports Medicine, 37(1), 73-94.

Hertel, J. (2008). Sensorimotor deficits with ankle sprains and chronic ankle instability. Clinical Sports Medicine, 27, 353-370.

Hettle, D. (2013). The Effect of Kinesiotaping on Functional Performance in Chronic Ankle Instability - Preliminary Study. Clinical Research on Foot \& Ankle, 01(01).

Hiller, C. E., Refshauge, K. M., Bundy, A. C., Herbert, R. D., \& Kilbreath, S. L. (2006). The Cumberland ankle instability tool: a report of validity and reliability testing. Archives of Physical Medicine and Rehabilitation, 87(9), 1235-1241.

Hopkins, J. T., Brown, T. N., Christensen, L., \& Palmieri-Smith, R. M. (2009). Deficits in peroneal latency and electromechanical delay in patients with functional ankle instability. Journal of Orthopaedic Research, 27(12), 1541-1546.

Lee, B.-G., \& Lee, J.-H. (2015). Immediate effects of ankle balance taping with kinesiology tape on the dynamic balance of young players with functional ankle instability. Technology and Health Care, 23(3), 333-341.

Lee, S.-M., \& Lee, J.-H. (2017). The immediate effects of ankle balance taping with kinesiology tape on ankle active range of motion and performance in the Balance Error Scoring System. Physical Therapy in Sport, 25, 99-105. 
McGuine, T. A., Greene, J. J., Best, T., \& Leverson, G. (2000). Balance as a predictor of ankle injuries in high school basketball players. Clinical Journal of Sport Medicine, 10, 239-244.

Munn, J., Sullivan, S., \& Schneiders, A. (2010). Evidence of sensorimotor deficits in functional ankle instability: a systematic review with meta-analysis. Journal of Science and Medicine in Sport, 13(1), 2-12.

Paillard, T., \& Noé, F. (2015). Techniques and Methods for Testing the Postural Function in Healthy and Pathological Subjects. BioMed Research International.

Rojhani-Shirazi, Z., Amirian, S., \& Meftahi, N. (2015). Effects of Ankle Kinesio Taping on Postural Control in Stroke Patients. Journal of Stroke and Cerebrovascular Diseases, 24(11), $2565-2571$.

Seo, H.-D., Kim, M.-Y., Choi, J.-E., Lim, G.-H., Jung, S.-I., Park, S.-H., ... Lee, H.-Y. (2016). Effects of Kinesio taping on joint position sense of the ankle. Journal of Physical Therapy Science, 28(4), 1158-1160.

Shields, C. A., Needle, A. R., Rose, W. C., Swanik, C. B., \& Kaminski, T. W. (2013). Effect of elastic taping on postural control deficits in subjects with healthy ankles, copers, and individuals with functional ankle instability. Foot \& Ankle International, 34(10), 1427-1435.

Shiravi, Z., Talebian Moghadam, S., Hadian, M. R., \& Olyaei, G. (2017). Effect of cognitive task on postural control of the patients with chronic ankle instability during single and double leg standing. Journal of Bodywork and Movement Therapies, 21(1), 58-62. 
Simon, J., Garcia, W., \& Docherty, C. L. (2014). The Effect of Kinesio Tape on Force Sense in People With Functional Ankle Instability. Clinical Journal of Sport Medicine, 24(4), 289294.

Sousa, A. S. P., Leite, J., Costa, B., \& Santos, R. (2017). Bilateral Proprioceptive Evaluation in Individuals With Unilateral Chronic Ankle Instability. Journal of Athletic Training, 52(4), $360-367$.

Wang, Y., Gu, Y., Chen, J., Luo, W., He, W., Han, Z., \& Tian, J. (2018). Kinesio taping is superior to other taping methods in ankle functional performance improvement: a systematic review and meta-analysis. Clinical Rehabilitation, 026921551878044.

Williams, S., Whatman, C., Hume, P. A., \& Sheerin, K. (2012). Kinesio Taping in Treatment and Prevention of Sports Injuries: A Meta-Analysis of the Evidence for its Effectiveness. Sports Medicine, 42(2), 153-164.

Winter, D. (1995). Human balance and posture control during standing and walking. Gait \& Posture, 3(4), 193-214.

Winter, D., Patla, A., Rietdyk, S., \& Ishac, M. (2001). Ankle muscle stiffness in the control of balance during quiet standing. Journal of Neurophysioly, 85, 2630-2633.

Yen, S.-C., Folmar, E., Friend, K. A., Wang, Y.-C., \& Chui, K. K. (2018). Effects of kinesiotaping and athletic taping on ankle kinematics during walking in individuals with chronic ankle instability: A pilot study. Gait \& Posture, 66, 118-123. 


\section{Figures}

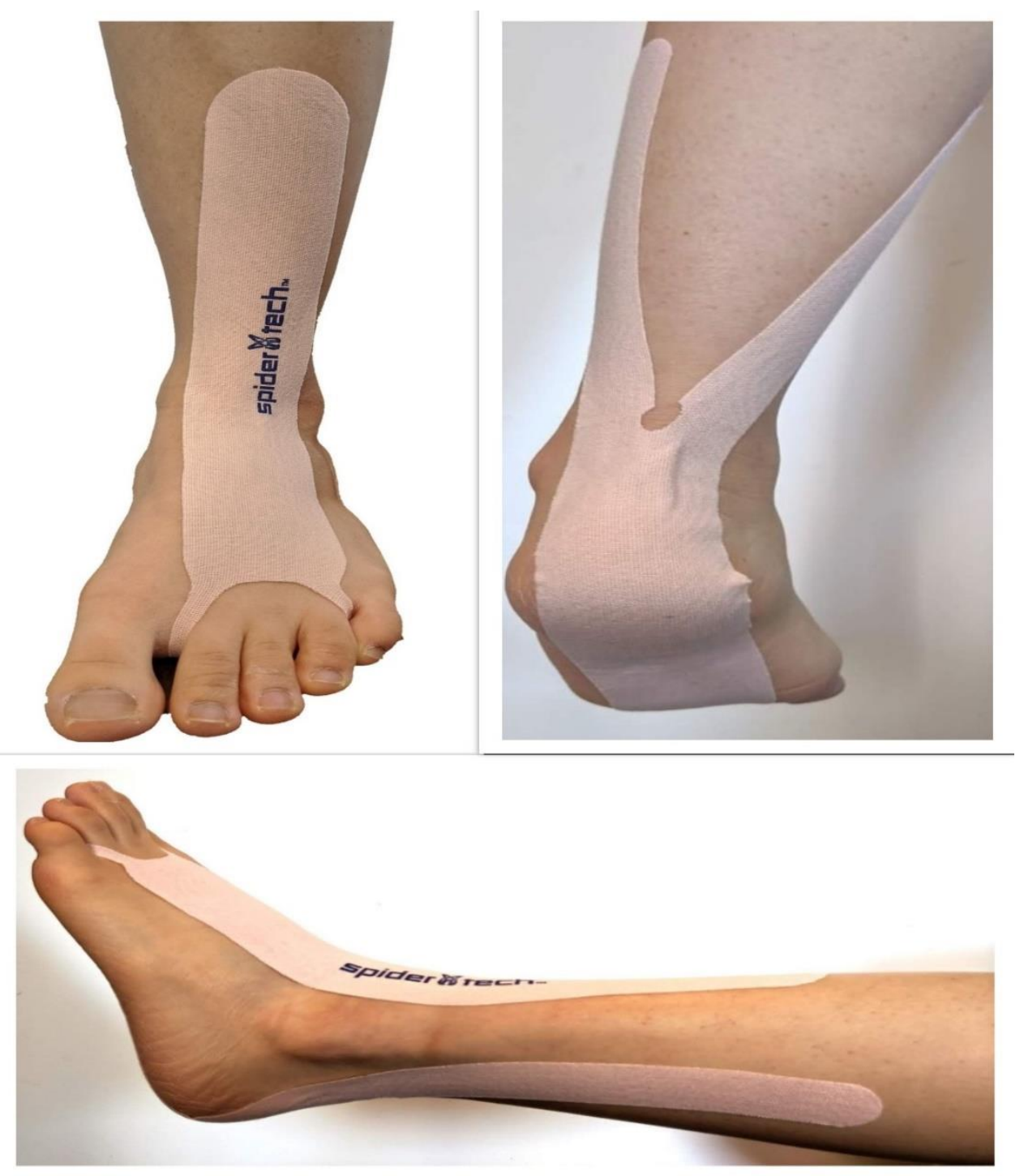

Figure 1. SpiderTech Ankle Pre-cut Kinesiology Tape application on participant's ankle. 


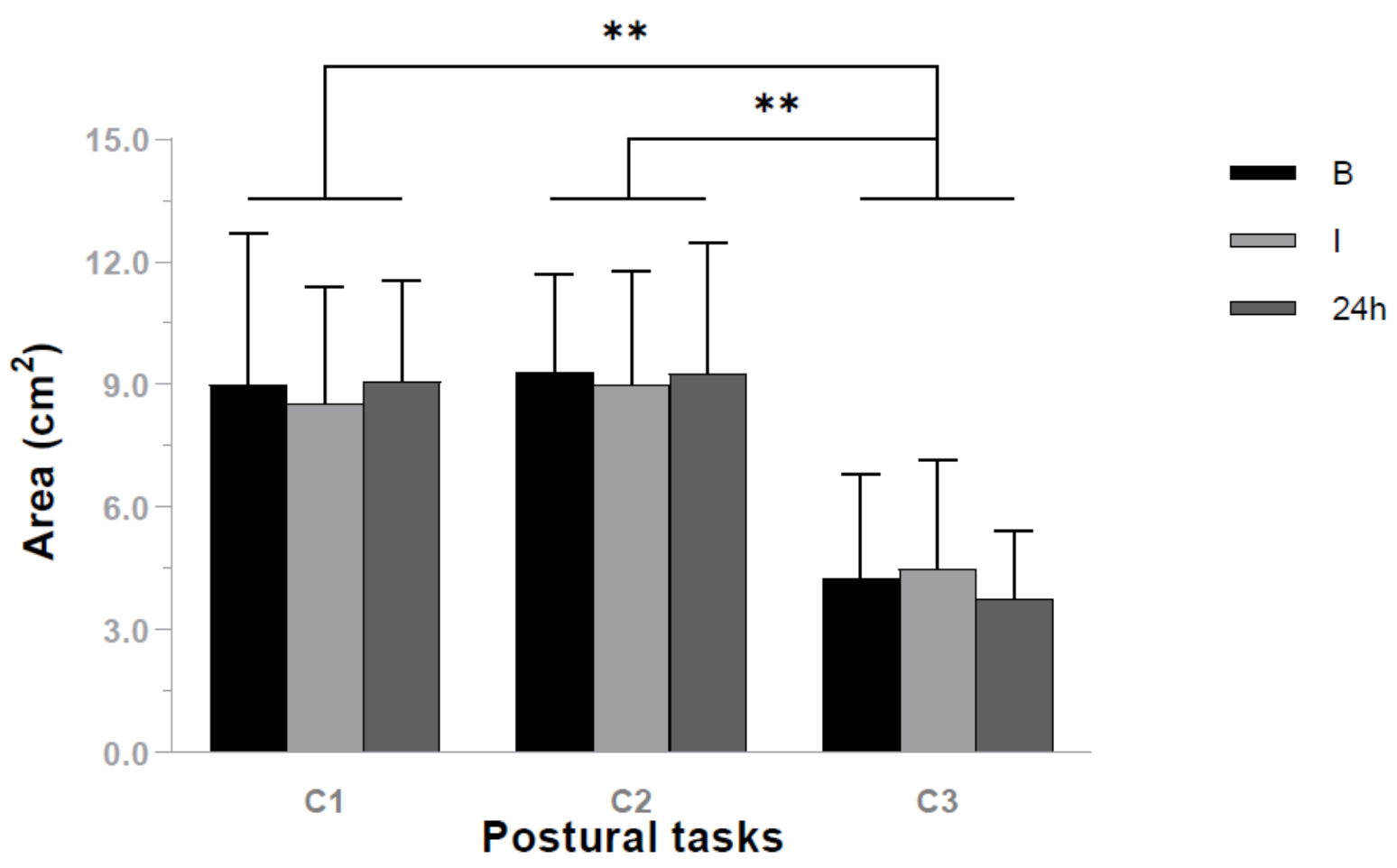

Figure 2. Mean and SD of area $(\mathrm{cm} 2)$ of all postural tasks measured in 3 different times (B=Baseline, I=Immediate after KT application, $24 \mathrm{~h}=24$ hours after KT application) $(* * \mathrm{p}<.001)$. 


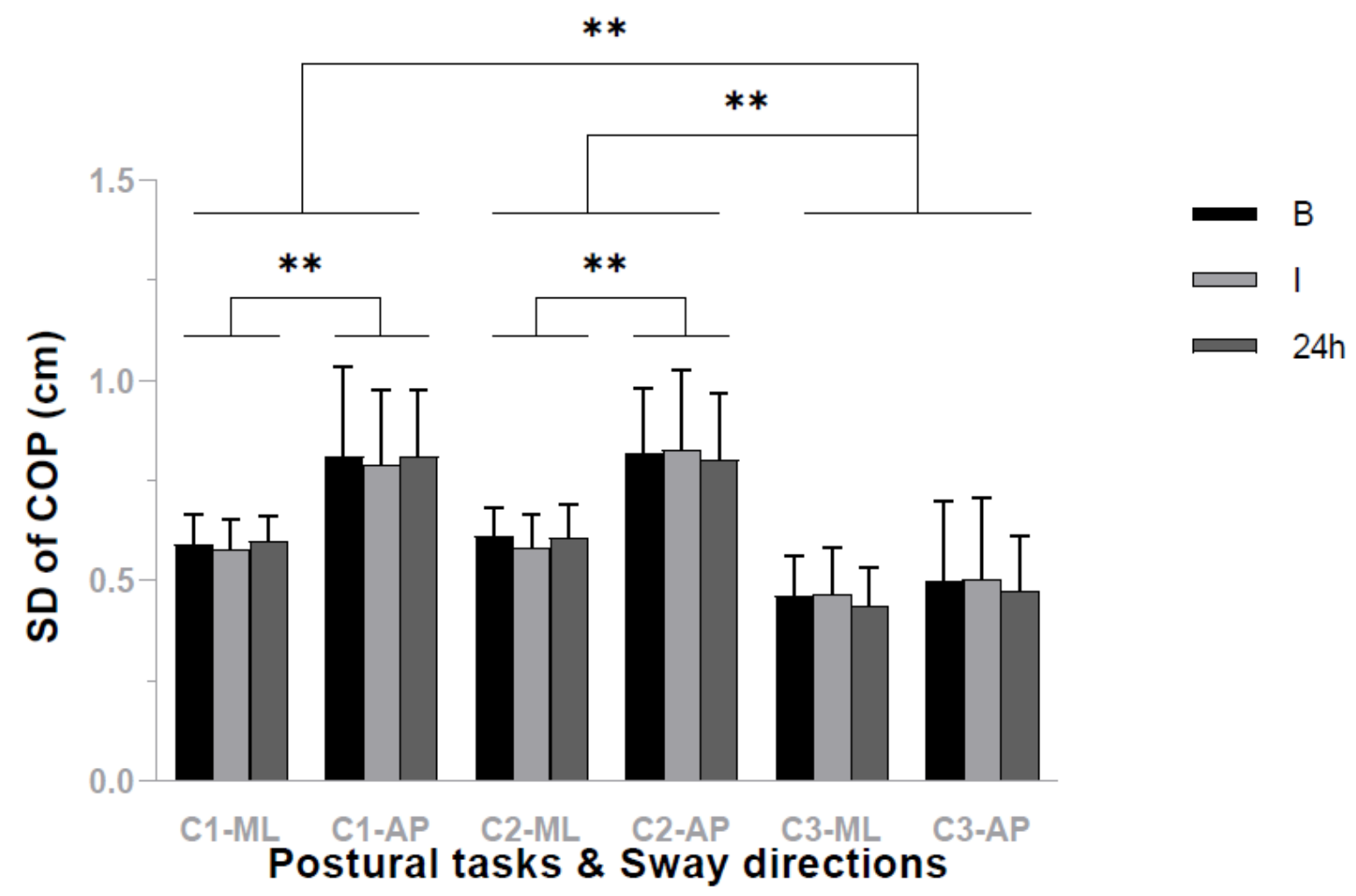

Figure 3. Mean and SD of SD of COP $(\mathrm{cm})$ in ML and AP directions of all postural tasks measured in 3 different times (B=Baseline, I=Immediate after KT application, $24 \mathrm{~h}=24$ hours after KT application) $(* \mathrm{p}<.05)(* * \mathrm{p}<.001)$. 


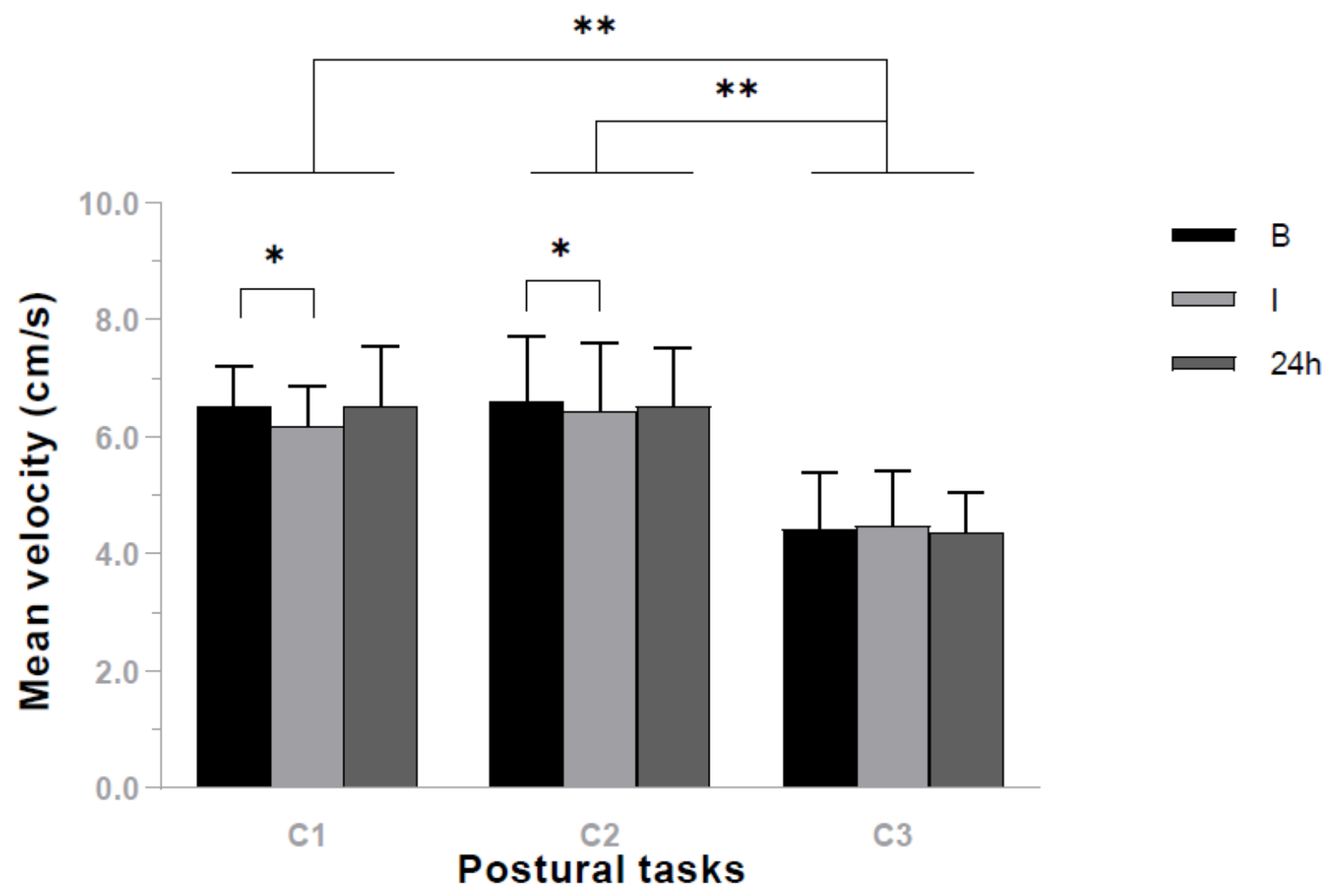

Figure 4. Mean and SD of mean velocity $(\mathrm{cm} / \mathrm{s})$ of all postural tasks measured in 3 different times ( $\mathrm{B}=$ Baseline, $\mathrm{I}=\mathrm{Immediate}$ after KT application, $24 \mathrm{~h}=24$ hours after KT application) (* $\mathrm{p}<.05)(* * \mathrm{p}<.001)$. 


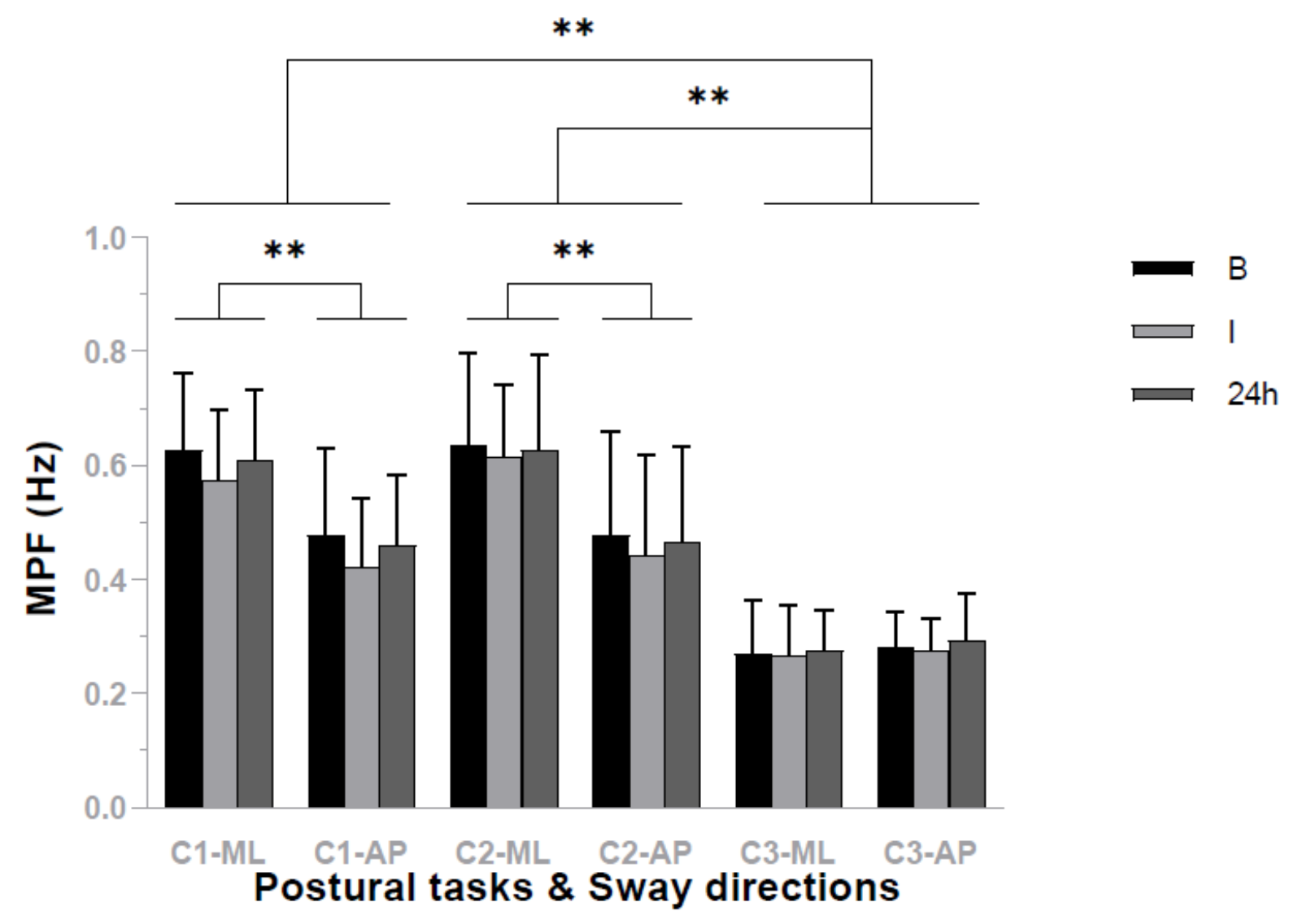

Figure 5. Mean and SD of MPF $(\mathrm{Hz})$ in both ML and AP directions of all postural tasks measured in 3 different times: B=Baseline, I=Immediate after KT application, $24 \mathrm{~h}=24$ hours after KT application $(* \mathrm{p}<.05)(* * \mathrm{p}<.001)$. 


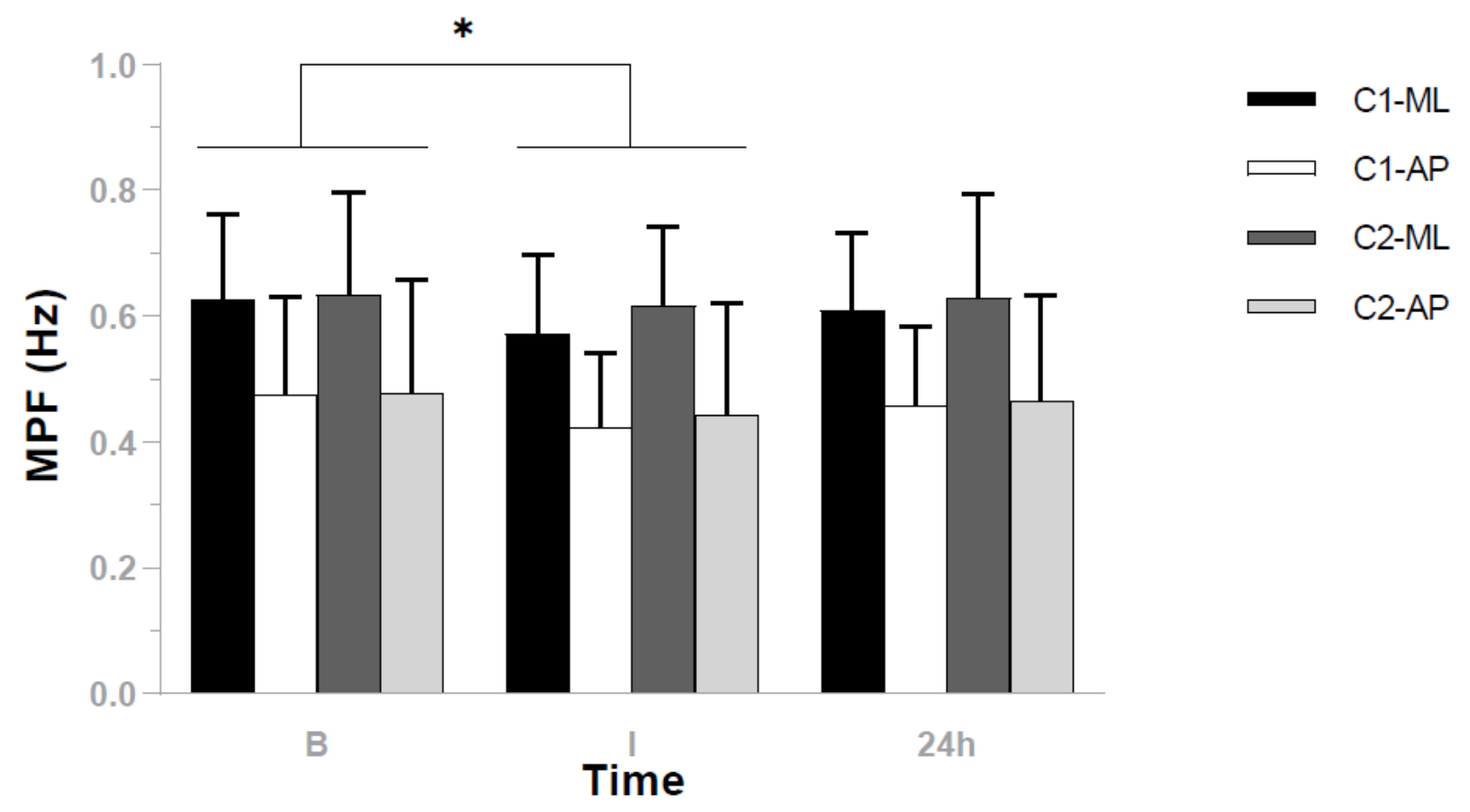

Figure 6. Mean and SD of MPF (Hz) in both ML and AP directions of 2 unipedal stances, $\mathrm{C} 1$ and $\mathrm{C} 2$, measured in 3 different times: $\mathrm{B}=$ Baseline, I=Immediate after $\mathrm{KT}$ application, $24 \mathrm{~h}=24$ hours after KT application $(* \mathrm{p}<.05)$. 


\section{CHAPTER FOUR: GENERAL DISCUSSION}

The purpose of the present experiment was to provide further empirical evidence of the role of Kinesiology Tape (KT) as a method of treating Functional ankle instability (FAI). Therefore, the main objective was to quantify the effects of the KT application on postural control in general-population individuals with FAI by accessing their performance in quiet standing tasks. Our first hypothesis was the KT application on the FAI ankle would improve participants' postural control in both unipedal and bipedal stance immediately after taping and 24 hours after taping with the taping remaining on the ankle. Secondly, we hypothesized that postural control of these participants would continue to improve at a period of 24 hours following the taping application compared to the immediate measurements. Thirdly, we hypothesized that postural control of the injured leg in the unipedal stance would be less stable than the uninjured leg, and the changes would only appear in the performance of the injured leg, which might indicate the effects of KT on the FAI ankle. Finally, our last hypothesis predicted the differences in sway directions in postural control between the bipedal stance and the unipedal stances.

\subsection{Effects of KT application on postural control in all standing tasks}

Proprioception has been defined as the positional sense of the joint that plays a massive role in the static human balance (Winter et al., 2001). The previous study in the population with ankle instability have shown that KT could enhance force sense (Simon, Garcia \& Docherty, 2014). Also, KT might help with dynamic balance in the Star Excursion Balance Test (SEBT) (Lee \& Lee, 2015), and foot kinematics during gait (Yen et al., 2018). Therefore, KT might alleviate the proprioceptive deficits as one of the characters of FAI (Munn et al., 2010) to provide more stability around the ankle area, which, in turn, might benefit postural control. 
However, the findings of the present study were not consistent with the body of literature and did not support our first three hypotheses. By assessing the performances of participants with FAI in static quiet standing tasks, the application of KT on their unstable ankle did not improve their postural control nor immediately after the tape application nor in 24 hours later with the tape remaining on the ankle. No improvement in postural control due to KT in this study was in line with the results of de-la-Torre-Domingo et al. (2015). They found that KT did not enhance postural control of their participants in static bipedal stance tasks.

\subsubsection{Postural control in bipedal stance versus in unipedal stance}

In all dependent variables, the bipedal stance differed significantly to the two unipedal stances. Precisely, our results showed that area, SD, mean velocity, and MPF were all significantly smaller in the bipedal stance compared to the unipedal stances. As we expected, the two stances are entirely different from each other: A bipedal stance, with a broader base of support, offered more stability than an unipedal stance (Winter, 1995), which resulted in a smaller area. Plus, the human body might have recognized a postural threat in unipedal stances (Carpenter et al., 2001). A more stable posture in a bipedal stance could justify why our results of MPF, the level of stiffness or co-contraction of the muscles around the ankle area, was significantly higher in the unipedal stances in both AP and ML directions compared to the bipedal stance (Fig. 5). These results also confirmed the use of co-contraction of muscles around the ankle area as the main postural control strategy in young adults in the unipedal stance (Kurz et al., 2018). On the other hand, the unipedal stances produced significantly more movements in both AP and ML directions and higher speed of regulations of the COP: higher SD (Fig. 3) and

mean velocity (Fig. 4). These results of MPF and SD confirmed our $4^{\text {th }}$ hypothesis, which predicted that postural control in the bipedal stance and the unipedal stances would be different 
in sway directions. Shiravi et al. (2017) found that the unipedal stances in their participants with ankle instability resulted in a higher mean velocity and a higher SD in AP direction compared to the bipedal stances. Dingenen et al. (2013) revealed that individuals with ankle instability possess an inferior ability to overcome postural perturbations; therefore, unipedal stances resulted in more regulations (i.e. higher mean velocity) and more stiffening (i.e. higher MPF). Plus, no research had examined the transfer of balance ability from one standing task to the other. In other words, as proposed in Henry's specificity hypothesis (Schmidt \& Wrisberg, 2008), one could perform well in the bipedal stance but could do worse in the unipedal stance and vice versa.

Interestingly, when looking at the performance of our participants in the unipedal stances, the results once again confirmed the contrast between SD and MPF: more movements variability (higher SD) correlates with less stiffness around the ankle joint (MPF) (Fig. $3 \& 5$ ). Our results showed a higher SD with a smaller MPF in AP direction and a smaller SD with a higher MPF in the ML direction. Unlike the results of Muehlbauer et al. (2014), our participants had more oscillations in the AP than ML direction to keep their balance. It could be explained based on the mechanical function of the ankle joint where the major muscles, tibialis anterior and gastrocnemius, are in charge. These muscles regulate the movements of dorsiflexion and plantarflexion of the ankle to help with balance. Therefore, postural control regulating movements happen in the AP direction because of the nature of those movements. Plus, the human body must have recognized a postural threat in the ML direction while performing the unipedal stance, which could explain the higher level of stiffness of MPF in this direction. 


\subsection{Effects of KT application on postural control in unipedal stances}

\subsubsection{Injured leg versus uninjured leg}

Hopkins et al. (2009) had examined FAI participants and discovered deficits in peroneal latency and electromechanical delay in the participants' leg with an unstable ankle (the injured leg) compared to the uninjured leg. Similarly, Konradsen and Magnusson (2000) found the FAI participants had significantly leg-to-leg difference of inversion-angle replication error of the ankle joint, which could indicate deficits in proprioception in the injured leg. Consequently, we would have expected to see a poorer postural control in the unipedal stance on the FAI leg compared to the uninjured side in the present study, as following our third hypothesis. Also, we predicted that the changes happened only in the performance of the injured leg, due to the possible effects of KT, in the unipedal stances through the experiment. However, our results did not support this hypothesis because the performances of the unipedal stances were similar between the legs in all measurement times (i.e. baseline to immediate to 24-hour period). By assessing the unipedal stance's performances of the participants, Evans et al. (2004) reported deficits in postural control in both lower limbs, injured and uninjured, of participants following an acute lateral ankle sprain. Without an appropriate rehabilitation program, an untreated acute lateral ankle sprain may lead to ankle instability (Miklovic et al., 2004). The participants of the present study never had any treatment for their ankles as one of the inclusion criteria. It could be the reason why they had developed into FAI. Sousa et al. (2017) indicated that the deficits in kinesthesia for the injured leg combined with the deficits in force sense for the uninjured leg could increase the risk of recurrence ankle injury in the FAI population. Plus, Shiravi et al. (2017) found no difference between the injured and uninjured leg in a quiet unipedal stance in participants with ankle instability. Therefore, this could explain why our results showed a similar 
postural control performance between two unipedal stances at baseline and why there could be room for improvements in both legs. That might have reflected in our results, which indicated that both $\mathrm{C} 1$ and $\mathrm{C} 2$ had led to changes in two variables. Precisely, mean velocity and MPF were significantly smaller at the immediate measurements compared to baseline (Fig. $4 \& 6$ ).

\subsubsection{Effects of KT on mean velocity and MPF}

Previous research concluded that improvements of postural control were reflected by a slower speed of postural regulation movements (i.e. mean velocity) and an increase of the level of stiffness around the ankle (i.e. MPF) (Paillard \& Noé, 2015). It suggests that in this study, KT might have imposed a mixed of positive effect (i.e. a slower mean velocity) and negative effect (i.e. a decreased MPF) to the participants' postural control only at the immediate time after the taping application. A study in 2015 (Lee \& Lee) found immediate improvements in the performance of SEBT in their participants with FAI. Another study (Lee \& Lee, 2017) argued about the positive effect of KT on providing more stability to participants while testing different static postural tasks on different surfaces. In all postural conditions, the authors also measured the ankle's range of motion (ROM) of participants before and after the taping application and obtained almost similar results. Similarly to other research (Lee \& Lee, 2015), they argued that KT, with its elastic property, may have helped postural control by enhancing the proprioception in the ankle area rather than by restricting the ankle joint structures. This phenomenon could be present in this study due to the design of the Ankle Pre-cut KT used in the taping procedure (Fig. 1), which allowed an even better range of motion of the ankle since SD and area did not change over time. The muscles around the ankle joint, peroneus longus and tibialis anterior, have essential roles in postural control but often show deficits in FAI patients (Ahn, Kim \& Kim, 2011; Donahue, Docherty \& Riley, 2014). Therefore, the positive change in mean velocity in this 
study could be due to some tension relief and proprioceptive enhancement to theses muscles offered by KT.

On the other hand, the immediate significant changes in MPF could rather be seen as interesting than as a negative effect. The decrease of the MPF level here suggests a reduction in stiffness around the ankle joint without compromising the overall performance of the unipedal stances (i.e. no significant changes in area and SD). Hubbard et al. (2004) discovered that FAI patients suffered similar mechanical laxity in the ankle joint as it is the main characteristic of mechanical ankle instability. Therefore, without a strict restriction like standard athletic tape, KT might have helped to stabilize the ankle joint, as mentioned before. With possible proprioceptive enhancement (i.e. significant decrease of mean velocity), this additional stability effect of KT to the mechanical structure of the ankle joint could help the human body to recognize the unipedal stance as less dangerous. Consequently, postural control of the participants became more stable and needed less of stiffening strategy with lower MPF. Unfortunately, the present study did not look specifically at any change in proprioception or in ROM at the ankle due to KT. Hence, it can neither be accepted nor rejected that KT may have these effects on the muscles and the ankle. Further research is merited to determine the underlying mechanisms of KT, if there are any, on the proprioception of the ankle in FAI individuals.

\subsubsection{Immediate or delayed effects or else?}

However, the immediate changes in mean velocity and MPF observed in this study did not support the theory of KT's delaying effects as being investigated in previous research. Similarly, Hettle et al. (2013) did not find any immediate effects of KT on their participants' unstable ankle using scores in the Star Excursion Balance Test as measurements. Moreover, Shields et al. (2013) did not notice relevant changes in their FAI participants' performance of the 
unipedal stance on the injured leg neither immediately after the KT application nor 24 hours later. However, another study on FAI individuals confirmed that wearing KT for 72 hours might have improved proprioceptive deficits in the unstable ankle area, reflected by a reduction of force sense errors (Simon et al., 2014). De-la-Torre-Domingo et al. (2015) pushed the limit even further when detecting improvements in their participants' dynamic balance only after seven days of having KT on the unstable ankle. Therefore, it was possible that theses immediate changes might have been the effects of adaptation. These participants could have got used to the difficulties of the postural tasks, especially the unipedal stances, after the trials of baseline. However, at the 24-hour mark, the fact that participants' performances on both legs did not differ from the baseline level nor the immediate measurements (Fig.6) rejected the long-term adaptation theory. Another possible explanation could relate to participants' perception of greater stability, confidence and reassurance when the tape was applied to the unstable ankle (Delahunt, McGrath et al., 2010). Consequently, participants in this study might have felt more confident immediately after the KT application, thus increasing their stability. Nonetheless, no measurements have been taken to support this claim in this study. 


\section{CHAPTER FIVE: CONCLUSION}

\subsection{Summary of findings}

In summary, our results showed no significant changes in all postural control measurements (i.e. area, SD, mean velocity and MPF) over time in both bipedal and unipedal stances. That suggests that the application of Kinesiology Tape to the unstable ankle did not lead to any meaningful improvements to the static postural control of young individuals with FAI, both immediately and 24 hours after the taping application. It was somewhat similar to the findings of Shields et al. (2013). The authors found improvements only in two variables after the KT application. Yet, because of the very small effect sizes associated with these variables, no definite conclusion on the benefits of KT on postural control could be drawn. Therefore, it remains unclear about the role of KT on human postural control in the FAI population. Furthermore, the effectiveness of $\mathrm{KT}$ as an adequate intervention and prevention method for ankle sprain and FAI stays uncertain. Though, the present study was the first one to focus on static postural control by utilizing pre-cut KT specialized for treating the ankle's injuries. Plus, with a lack of scientific evidence in the non-athlete population, this study contributed to a better understanding of the role of KT to human musculoskeletal injuries, especially the ankle sprain and FAI. A study of Elshemy and Battecha (2013) saw the positive effects of KT, when coupled with a treatment program of proprioceptive training, on dynamic position sense of the ankle and eversion to inversion strength in young boys with FAI. In conclusion, they suggested that both $\mathrm{KT}$ and the treatment program were useful for FAI patients, but praised the proprioceptive training over the Kinesiology Tape as it could be more regularly scheduled in the rehabilitation for those patients. Henceforth, as KT has become more accessible than ever, all of the theoretical effects of KT warrant further investigation because the potential for Kinesiology Tape to play a 
part in the rehabilitation of FAI individuals could be crucial in the future for everyone, both athletes and non-athletes.

\subsection{Limitations}

The research approach was designed to reduce limitations, but some might still exist. The population of interest did not consider participants' lifestyles. Even the cut-off was 5 hours or less of physical activity per week as an exclusion criterion, a little more active participants could already be better in postural control compared to sedentary participants. Due to the mixture of the personal fitness level of the participants, the mean effects of KT tape might not have been highly noticeable.

Next, the CAIT might not have reflected the state of FAI in our participants entirely. In other words, even the cut-off was 27 points or below to be categorized as FAI, our participants' scores ranged from 11 to 25 points, and we could not tell the difference between a person with a lower score to another with higher score. In this case, we ask if the person with a lower score could have his or her ankle very severely functional unstable, and this could already affect our results. The possibility is inevitable, but we did our best following the guideline of CAIT as being done in previous research. It suggests that future research can take this into consideration in the recruitment of participants to limit the possible effect of between-subject differences to the results.

The present study was the first to try pre-cut KT dedicated to treating the ankle. Therefore, this might have had some influences over the results. However, this kind of pre-cut tape should be used more in future research as its application is user-friendly. Importantly, it will 
help with the standardization for the type of Kinesiology tape (i.e., self-cut vs. pre-cut, different materials, different shapes) and the application techniques in research.

Further, due to differences in neuromuscular ability between dominant and non-dominant limbs, this could be a confounding factor in performance considering a quarter of the participants in this study had a functionally unstable ankle on their non-dominant leg. Finally, scientists have been using the surface EMG to reveal nerve-to-muscle signal transmission. It could be an excellent co-measure for research of KT, especially in the pathological population like FAI. They present neuromuscular deficits in the muscles around the ankle area (e.g. longer peroneal reflex latency time) that could put them more at risk of a lateral ankle sprain. Therefore, changes in EMG signals could indicate the effects of $\mathrm{KT}$. 


\section{REFERENCES}

Ahn, C. S., Kim, H. S., \& Kim, M. C. (2011). The Effect of the EMG Activity of the Lower Leg with Dynamic Balance of the Recreational Athletes with Functional Ankle Instability. Journal of Physical Therapy Science, 23(4), 579-583.

Bailey, D., \& Firth, P. (2017). Does kinesiology taping of the ankles affect proprioceptive control in professional football (soccer) players? Physical Therapy in Sport, 25, 94-98.

Beckman, S., \& Buchanan, T. (1995). Ankle inversion injury and hypermobility: effect on hip and ankle muscle electromyography onset latency. Archives of Physical Medicine and Rehabilation, 76, 1138-1143.

Bicici, S., Karatas, N., \& Baltaci, G. (2012). Effect of athletic taping and kinesiotaping on measurements of functional performance in basketball players with chronic inversion ankle sprains, The International Journal of Sports Physical Therapy, 7(2),13.

Bielska, I. A., Wang, X., Lee, R., \& Johnson, A. P. (2017). The health economics of ankle and foot sprains and fractures: A systematic review of English-language published papers. Part 2: The direct and indirect costs of injury. The Foot, S0958259217301402.

Bot, S., \& Mechelen, W. (1999). The effect of ankle bracing on athletic performance. Sports Medicine, 27(3), 171-178.

Carpenter, M., Frank, J., Silcher, C., \& Peysar, G. (2001). The influence of postural threat on the control of upright stance. Experimental Brain Research, 138(2), 210-218.

Carpenter, M. G., Murnaghan, C. D., \& Inglis, J. T. (2010). Shifting the balance: Evidence of an exploratory role for postural sway. Neuroscience, 171(1), 196-204. 
Chiari, L., Rocchi, L., \& Cappello, A. (2002). Stabilometric parameters are affected by anthropometry and foot placement. Clinical Biomechanics (Bristol, Avon), 17(9-10), 666677.

Chomiak, T., Pereira, F. V., \& Hu, B. (2015). The Single-Leg-Stance Test in Parkinson's Disease. Journal of Clinical Medicine Research, 7(3), 182-185.

Cordova, M. L. (2002). Efficacy of prophylactic ankle support: an experimental perspective. Journal of Athletic Training, 37, 446-457

Delahunt, E., Coughlan, G. F., Caulfield, B., Nightingale, E. J., Lin, C.-W. C., \& Hiller, C. E. (2010). Inclusion Criteria When Investigating Insufficiencies in Chronic Ankle Instability. Medicine \& Science in Sports \& Exercise, 42(11), 2106-2121.

Delahunt, E., McGrath, A., Doran, N., Coughlan, G.F. (2010). Effect of taping on actual and perceived dynamic postural stability in persons with chronic ankle instability. Archives of Physical Medicine and Rehabilitation, 91, 1383-1389.

de-la-Torre-Domingo, C., Alguacil-Diego, I. M., Molina-Rueda, F., López-Román, A., \& Fernández-Carnero, J. (2015). Effect of Kinesiology Tape on Measurements of Balance in Subjects With Chronic Ankle Instability: A Randomized Controlled Trial. Archives of Physical Medicine and Rehabilitation, 96(12), 2169-2175.

De Ridder, R., Willems, T., Vanrenterghem, J., Verrelst, R., De Blaiser, C., \& Roosen, P. (2020). Taping Benefits Ankle Joint Landing Kinematics in Subjects With Chronic Ankle Instability. Journal of Sport Rehabilitation, 29(2), 162-167. 
Deschamps, K., Dingenen, B., Pans, F., Van Bavel, I., Matricali, G. A., \& Staes, F. (2016). Effect of taping on foot kinematics in persons with chronic ankle instability. Journal of Science and Medicine in Sport, 19(7), 541-546.

Dingenen, B., Staes, F. F., \& Janssens, L. (2013). A new method to analyze postural stability during a transition task from double-leg stance to single-leg stance. Journal of Biomechanics, 46(13), 2213-2219.

Dizon, J. M. R., \& Reyes, J. J. B. (2010). A systematic review on the effectiveness of external ankle supports in the prevention of inversion ankle sprains among elite and recreational players. Journal of Science and Medicine in Sport, 13(3), 309-317.

Doherty, C., Bleakley, C., Delahunt, E., \& Holden, S. (2017). Treatment and prevention of acute and recurrent ankle sprain: an overview of systematic reviews with meta-analysis. British Journal of Sports Medicine, 51(2), 113-125.

Doherty, C., Delahunt, E., Caulfield, B., Hertel, J., Ryan, J., \& Bleakley, C. (2014). The incidence and prevalence of ankle sprain injury: a systematic review and meta-analysis of prospective epidemiological studies. Sports Medicine (Auckland, N.Z.), 44(1), 123-140.

Docherty, C. L., Valovich McLeod, T. C., \& Shultz, S. J. (2006). Postural Control Deficits in Participants with Functional Ankle Instability as Measured by the Balance Error Scoring System: Clinical Journal of Sport Medicine, 16(3), 203-208.

Donahue, M. S., Docherty, C. L., \& Riley, Z. A. (2014). Decreased fibularis reflex response during inversion perturbations in FAI subjects. Journal of Electromyography and Kinesiology, 24(1), 84-89. 
Duarte, M., \& Freitas, S. M. S. F. (2010). Revision of posturography based on force plate for balance evaluation. Revista Brasileira de Fisioterapia, 14(3), 183-192.

Elshemy, S. A. \& Battecha, K. H. (2013). Kinesio Taping Versus Proprioceptive Training on Dynamic Position Sense of the Ankle and Eversion to Inversion Strength Ratios in Children with Functional Ankle Instability. Medical Journal of Cairo University, 81(2), 61-68.

Evans, T., Hertel, J. \& Sebastianelli, W. (2004). Bilateral deficits in postural control following lateral ankle sprain. Foot Ankle International, 25 (11), 833-839.

Fong, D., Hong, Y., Chan, L. K., et al. (2007). A systematic review on ankle injury and ankle sprain in sports. Sports Medicine, 37(1), 73-94.

Freeman, M. A., Dean, M. R., \& Hanham, I. W. (1965). The etiology and prevention of functional instability of the foot. The Journal of Bone and Joint Surgery. British Volume, $47(4), 678-685$.

Halim-Kertanegara, S., Raymond, J., Hiller, C. E., Kilbreath, S. L., \& Refshauge, K. M. (2017). The effect of ankle taping on functional performance in participants with functional ankle instability. Physical Therapy in Sport, 23, 162-167.

Halseth, T., McChesney, J. W., DeBeliso, M., Vaughn, R., \& Lien, J. (2004). The Effects of Kinesio $^{\text {TM }}$ Taping on Proprioception at the Ankle. Journal of Sports Science \& Medicine, $3(1), 1-7$.

Hertel, J. (2002). Functional anatomy, pathomechanics, and pathophysiology of lateral ankle instability. Journal of Athletic Training, 37, 364-375 
Hertel, J. (2008). Sensorimotor deficits with ankle sprains and chronic ankle instability. Clinical Sports Medicine, 27, 353-370.

Hettle, D. (2013). The Effect of Kinesiotaping on Functional Performance in Chronic Ankle Instability - Preliminary Study. Clinical Research on Foot \& Ankle, 01(01).

Hiller, C. E., Refshauge, K. M., Bundy, A. C., Herbert, R. D., \& Kilbreath, S. L. (2006). The Cumberland ankle instability tool: a report of validity and reliability testing. Archives of Physical Medicine and Rehabilitation, 87(9), 1235-1241.

Hopkins, J. T., Brown, T. N., Christensen, L., \& Palmieri-Smith, R. M. (2009). Deficits in peroneal latency and electromechanical delay in patients with functional ankle instability. Journal of Orthopaedic Research, 27(12), 1541-1546.

Hopper, D., Samsson, K., Hulenik, T., Ng, C., Hall, T., \& Robinson, K. (2009). The influence of Mulligan ankle taping during balance performance in subjects with unilateral chronic ankle instability. Physical Therapy in Sport, 10(4), 125-130.

Horak, F. B. (2006). Postural orientation and equilibrium: what do we need to know about neural control of balance to prevent falls? Age and Ageing, 35 Supply 2, ii7-ii11.

Hubbard, T., Kaminski, T., Vander Griend, B., \& Kovaleski, J. (2004). Quantitative assessment of mechanical laxity in the functionally unstable ankle. Medicine \& Science in Sports \& Exercise, 36, 760-766.

Jonsson, E., Seiger, Å., \& Hirschfeld, H. (2004). One-leg stance in healthy young and elderly adults: A measure of postural steadiness? Clinical Biomechanics, 19(7), 688-694. 
Kazemi, K., Arab, A. M., Abdollahi, I., López-López, D., \& Calvo-Lobo, C. (2017).

Electromiography comparison of distal and proximal lower limb muscle activity patterns during external perturbation in subjects with and without functional ankle instability. Human Movement Science, 55, 211-220.

Kerkhoffs, G. M., van den Bekerom, M., Elders, L. A. M., van Beek, P. A., Hullegie, W. A. M., Bloemers, G. M. F. M., ... de Bie, R. A. (2012). Diagnosis, treatment and prevention of ankle sprains: an evidence-based clinical guideline. British Journal of Sports Medicine, 46(12), 854-860.

Kim, K.-J., \& Heo, M. (2015). Effects of virtual reality programs on balance in functional ankle instability. Journal of Physical Therapy Science, 27(10), 3097-3101.

Kim, K.-J., Kim, Y.-E., Jun, H.-J., Lee, J.-S., Ji, S.-H., Ji, S.-G., .. Kim, Y.-O. (2014). Which Treatment is More Effective for Functional Ankle Instability: Strengthening or Combined Muscle Strengthening and Proprioceptive Exercises? Journal of Physical Therapy Science, 26(3), 385-388.

Konradsen, L. (2002). Factors contributing to chronic ankle instability: Kinesthesia and joint position sense. Journal of Athletic Training, 37(4), 381-385.

Konradsen, L., Olesen, S., \& Hansen, H. (1998). Ankle sensorimotor control and eversion strength after acute ankle inversion injuries. American Journal of Sports Medicine, 26(1), 7277.

Konradsen, L., \& Magnusson, P. (2000). Increased inversion angle replication error in functional ankle instability. Knee Surgery, Sports Traumatology, Arthroscopy, 8(4), 246-251. 
Kouvelioti, V., Kellis, E., Kofotolis, N., \& Amiridis, I. (2015). Reliability of Single-leg and Double-leg Balance Tests in Subjects with Anterior Cruciate Ligament Reconstruction and Controls. Research in Sports Medicine, 23(2), 151-166.

Kuijt, M., Inklaar, H., Gouttebarge, V., \& Frings-Dresen, M. (2012) Knee and ankle osteoarthritis in former elite soccer players: a systematic review of the recent literature. Journal of Science and Medicine in Sport, 15, 480-487.

Kuni, B., Mussler, J., Kalkum, E., Schmitt, H., \& Wolf, S. I. (2016). Effect of kinesiotaping, non-elastic taping and bracing on segmental foot kinematics during drop landing in healthy subjects and subjects with chronic ankle instability. Physiotherapy, 102(3), 287-293.

Kurz, E., Faude, O., Roth, R., Zahner, L., \& Donath, L. (2018). Ankle muscle activity modulation during single-leg stance differs between children, young adults and seniors. European Journal of Applied Physiology, 118(2), 239-247.

Laatar, R., Kachouri, H., Borji, R., Rebai, H., \& Sahli, S. (2018). Combined physical-cognitive training enhances postural performances during daily life tasks in older adults. Experimental Gerontology, 107, 91-97.

Lajoie, Y., Richer, N., Jehu, D. A., Polskaia, N., \& Saunders, D. (2016). Letter to the Editor: On "Advantages and disadvantages of stiffness instructions when studying postural control" by C.T. Bonnet: You just can't win: Advantages and disadvantages of the postural stability requirement. Gait and Posture, 46(October 2018), 215-218.

Lee, B.-G., \& Lee, J.-H. (2015). Immediate effects of ankle balance taping with kinesiology tape on the dynamic balance of young players with functional ankle instability. Technology and Health Care, 23(3), 333-341. 
Lee, S.-M., \& Lee, J.-H. (2017). The immediate effects of ankle balance taping with kinesiology tape on ankle active range of motion and performance in the Balance Error Scoring System. Physical Therapy in Sport, 25, 99-105.

Levangie, P. K., \& Norkin, C. C. (2001). Joint Structure and Function: A Comprehensive Analysis. 3rd Ed. Philadelphia, PA: F.A. Davis.

Maki, B., Holliday, P., \& Topper, A. (1994). A prospective study of postural balance and risk of falling in an ambulatory and independent elderly population. Journal of Gerontology, 49(2), M72-84.

McGuine, T. A., Greene, J. J., Best, T., \& Leverson, G. (2000). Balance as a predictor of ankle injuries in high school basketball players. Clinical Journal of Sport Medicine, 10, 239-244.

McKay, G., Goldie, P., Payne, W., \& Oakes, B. (2001). Ankle injuries in basketball: injury rate and risk factors. British Journal of Sports Medicine, 35, 103-108.

McNevin, N. H., Shea, C. H., \& Wulf, G. (2003). Increasing the distance of an external focus of attention enhances learning. Psychological Research Psychologische Forschung, 67, 22-29.

Miklovic, T. M., Donovan, L., Protzuk, O. A., Kang, M. S., \& Feger, M. A. (2018). Acute lateral ankle sprain to chronic ankle instability: A pathway of dysfunction. The Physician and Sportsmedicine, 46(1), 116-122.

Muehlbauer, T., Mettler, C., Roth, R., \& Granacher, U. (2014). One-Leg Standing Performance and Muscle Activity: Are There Limb Differences? Journal of Applied Biomechanics, 30(3), 407-414. 
Munn, J., Sullivan, S., \& Schneiders, A. (2010). Evidence of sensorimotor deficits in functional ankle instability: a systematic review with meta-analysis. Journal of Science and Medicine in Sport, 13(1), 2-12.

Nakajima, M., \& Baldridge, C. (2013). The effect of kinesio® tape on vertical jump and dynamic postural control. International Journal of Sports Physical Therapy, 8(4), 393-406.

Paillard, T., \& Noé, F. (2015). Techniques and Methods for Testing the Postural Function in Healthy and Pathological Subjects. BioMed Research International.

Patel, M., Gomez, S., Berg, S., Almbladh, P., Lindblad, J., Petersen, H., ... Fransson, P. (2008). Effects of 24-h and 36-h sleep deprivation on human postural control and adaptation. Experimental Brain Research, 185(2), 165-173.

Perrin, P., Bene, M., Perrin, C., \& Durupt, D. (1997). Ankle trauma significantly impairs postural control- a study in basketball players and controls. International Journal of Sports Medicine, $18,387-392$.

Peterka, R. (2002). Sensorimotor integration in human postural control. Journal of Neurophysiology, 88(3), 1097-118.

Pollock, A., Durward, B., Rowe, P., \& Paul, J. (2000). What is balance? Clinical Rehabilitation, 14(4), 402-406.

Raymond, J., Nicholson, L., Hiller, C., \& Refshauge, K. (2012). The effect of ankle taping or bracing on proprioception in functional ankle instability: A systematic review and metaanalysis. Journal of Science and Medicine in Sport, 15(5), 386-392. 
Refshauge, K., Kilbreath, S., \& Raymond J. (2003). Deficits in detection of inversion and eversion movements among subjects with recurrent ankle sprains. Journal of Orthopaedic and Sports Physical Therapy, 33(4), 166-73, discussion 173-6.

Richer, N., Saunders, D., Polskaia, N., \& Lajoie, Y. (2017). The effects of attentional focus and cognitive tasks on postural sway may be the result of automaticity. Gait \& Posture, 54, 4549.

Riemann, B. L., \& Lephart, S. M. (2002). The sensorimotor system. part II. the role of proprioception in motor control and functional joint stability. Journal of Athletic Training, $37(1), 80-84$.

Rojhani-Shirazi, Z., Amirian, S., \& Meftahi, N. (2015). Effects of Ankle Kinesio Taping on Postural Control in Stroke Patients. Journal of Stroke and Cerebrovascular Diseases, 24(11), 2565-2571.

Samuel, A. J., Solomon, J., \& Mohan, D. (2015). A Critical Review on the Normal Postural Control. Physiotherapy and Occupational Therapy Journal, 8(2), 71-5.

Schmidt, R. A., \& Wrisberg, C. A. (2008). Motor Learning and Performance: A Situation-based Learning Approach. Human Kinetics.

Scoppa, F., Capra, R., Gallamini, M., \& Shiffer, R. (2013). Clinical stabilometry standardization. Basic definitions - Acquisition interval - Sampling frequency. Gait and Posture, 37(2), 290292. 
Semple, S., Esterhuysen, C., \& Grace, J. (2012). The Effects of Kinesio Ankle Taping on Postural Stability in Semiprofessional Rugby Union Players. Journal of Physical Therapy Science, 24(12), 1239-1242.

Seo, H.-D., Kim, M.-Y., Choi, J.-E., Lim, G.-H., Jung, S.-I., Park, S.-H., ... Lee, H.-Y. (2016). Effects of Kinesio taping on joint position sense of the ankle. Journal of Physical Therapy Science, 28(4), 1158-1160.

Shields, C. A., Needle, A. R., Rose, W. C., Swanik, C. B., \& Kaminski, T. W. (2013). Effect of elastic taping on postural control deficits in subjects with healthy ankles, copers, and individuals with functional ankle instability. Foot \& Ankle International, 34(10), 1427-1435.

Shiravi, Z., Talebian Moghadam, S., Hadian, M. R., \& Olyaei, G. (2017). Effect of cognitive task on postural control of the patients with chronic ankle instability during single and double leg standing. Journal of Bodywork and Movement Therapies, 21(1), 58-62.

Shumway-Cook, A., \& Woollacott, M. H. (1995). Motor Control: Theory and Practical Applications. Williams \& Wilkins.

Simon, J., Garcia, W., \& Docherty, C. L. (2014). The Effect of Kinesio Tape on Force Sense in People With Functional Ankle Instability. Clinical Journal of Sport Medicine, 24(4), 289294.

Soavi, R., Girolami, M., Loreti, I, Bragonzoni, L., Monti, C., Visani, A., \& Marcacci, M. (2000). The mobility of the proximal tibio-fibular joint. A roentgen stereophotogrammetric analysis on six cadaver specimens. Foot Ankle Int, 21(4), 336-342. 
Springer, B. A., Marin, R., Cyhan, T., Roberts, H., \& Gill, N. W. (2007). Normative Values for the Unipedal Stance Test with Eyes Open and Closed: Journal of Geriatric Physical Therapy, 30(1), 8-15.

Steinberg, N., Adams, R., Ayalon, M., Dotan, N., Bretter, S., \& Waddington, G. (2018). Recent ankle injury, sport participation level and tests of proprioception. Journal of Sport Rehabilitation, 1-25.

Stins, J. F., \& Beek, P. J. (2012). A critical evaluation of the cognitive penetrability of posture. Experimental Aging Research, 38, 208-219.

Tropp, H., Odenrick, P., \& Gillquist, J. (1985). Stabilometry recordings in functional and mechanical instability of the ankle joint. International Journal of Sports Medicine, 6, 180182.

Turner, A., Barlow, J., \& Heathcote-Elliot, C. (2000). Long term health impact of playing professional football in the United Kingdom. British Journal of Sports Medicine, 34, 332337.

Van Deun, S., Staes, F. F., Stappaerts, K. H., Janssens, L., Levin, O., \& Peers, K. K. H. (2007). Relationship of Chronic Ankle Instability to Muscle Activation Patterns during the Transition from Double-Leg to Single-Leg Stance. The American Journal of Sports Medicine, 35(2), $274-281$.

Wang, Y., Gu, Y., Chen, J., Luo, W., He, W., Han, Z., \& Tian, J. (2018). Kinesio taping is superior to other taping methods in ankle functional performance improvement: a systematic review and meta-analysis. Clinical Rehabilitation, 026921551878044. 
Wikstrom, E., Arrigenna, M., Tillman, M., \& Borsa, P. (2006). Dynamic Postural Stability in Subjects with Braced, Functionally Unstable Ankles. Journal of Athletic Training, 41(3), $245-250$.

Williams, S. A., Ng, L., Stephens, N., Klem, N., \& Wild, C. (2018). Effect of prophylactic ankle taping on ankle and knee biomechanics during basketball-specific tasks in females. Physical Therapy in Sport, 32, 200-206.

Williams, S., Whatman, C., Hume, P. A., \& Sheerin, K. (2012). Kinesio Taping in Treatment and Prevention of Sports Injuries: A Meta-Analysis of the Evidence for its Effectiveness. Sports Medicine, 42(2), 153-164.

Winter, D. (1995). Human balance and posture control during standing and walking. Gait \& Posture, 3(4), 193-214.

Winter, D., Prince, F. \& Patla, A. (1997). Validity of the inverted pendulum model of balance in quiet standing. Gait Posture, 5, 153-154

Winter, D., Patla, A., Prince, F., Ishac, M., \& Gieloperczak, K. (1998). Stiffness control of balance in quiet standing. Journal of Neurophysiology, 80(3), 1211-1221.

Winter, D., Patla, A., Rietdyk, S., \& Ishac, M. (2001). Ankle muscle stiffness in the control of balance during quiet standing. Journal of Neurophysioly, 85, 2630-2633.

Wulf, G., McNevin, N., \& Shea, C. H. (2001). The automaticity of complex motor skill learning as a function of attentional focus. The Quarterly Journal of Experimental Psychology: Section A, 54, 1143-1154. 
Yasui, Y., Murawski, C. D., Wollstein, A., Takao, M., \& Kennedy, J. G. (2016). Operative Treatment of Lateral Ankle Instability. JBJS Reviews, 4(5), 1.

Yeung, M., Chan, K., So, C., Yuan, W. (1994). An epidemiological survey on ankle sprain. British Journal Sports Medicine, 28(2), 112-116.

Yen, S.-C., Folmar, E., Friend, K. A., Wang, Y.-C., \& Chui, K. K. (2018). Effects of kinesiotaping and athletic taping on ankle kinematics during walking in individuals with chronic ankle instability: A pilot study. Gait \& Posture, 66, 118-123. 


\title{
Appendix. SpiderTech Ankle Pre-cut Kinesiology Tape application
}

\author{
instructions.
}

\section{ANKLE SPIDER ${ }^{\mathrm{TM}}$ \\ basic application}

Helps with

the following

\section{conditions:}

Shin splints

Ankle sprains

Ankle instability

- Improved athletic performance

- Postoperative rehabilitation

Arthritis

- Plantar fasciitis

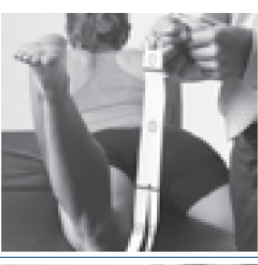

1 Have the client lying comfortably on their stomach with the bottom of the foot accessible. Tear all of the perforations along the black lines on the back of the application.

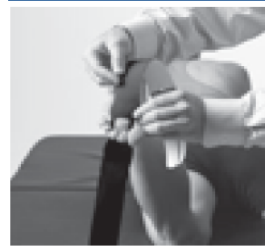

Place the application through the toes with one strip between the big toe and second toe and the second strip between the third/fourth or forth/fifth toes, depending on foot size.

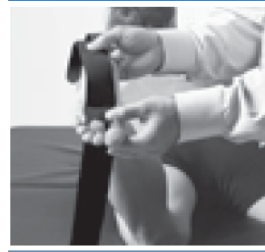

Remove the backing of section 1 and gently lay down on the bottom of the foot. Gently rub over top of the tape to activate the glue.

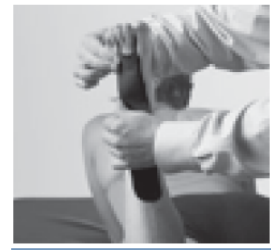

Bring the top of the foot into view by plantar flexing the foot. Remove the backing of section 2 and gently lay down on the top of the foot. Gently rub over top of the tape to activate the glue.

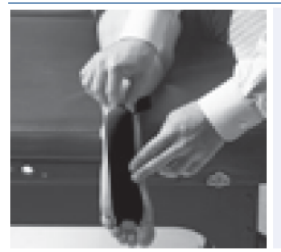

Then, with the bottom of the foot exposed, stretch the plantar fascia and remove the backing of section 3 as you lay the tape down over the arch of the foot without any stretch in the tape. Gently rub over top of the tape to activate the glue.

\section{spider if tech.}




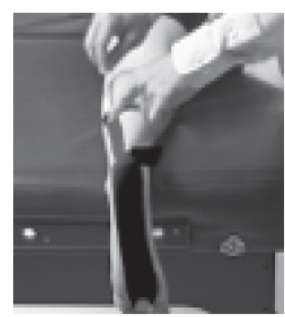

With the leg fully extended and the ankle dorsiflexed to stretch the Achilles tendon and calf muscles, start gently pealing the backing of section 4 on the outside as you lay the tape down on the outside border of the Achilles tendon and up the calf until the entire section is completed. Cently rub over top of the tape to activate the glue.

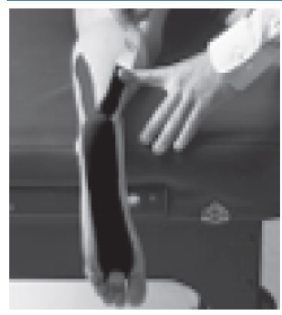

7 Repeat step 8 with the inside section 4. Gently rub over top of the tape to activate the glue.

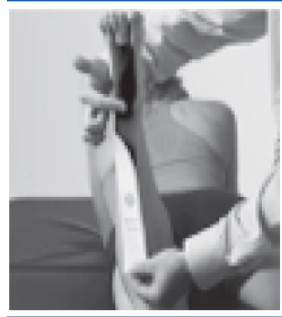

8 Now flex the knee bringing the clients heel toward their butt and plantar flex the foot gently to stretch the tibialis anterior. Cently peel back the backing of section 5 as you lay the tape down over the top of the foot and up the anterior shin along the tibialis anterior without any stretch.

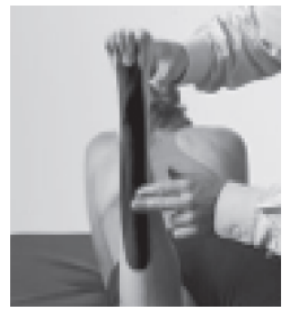

9 Cently rub over top of the tape to activate the glue.
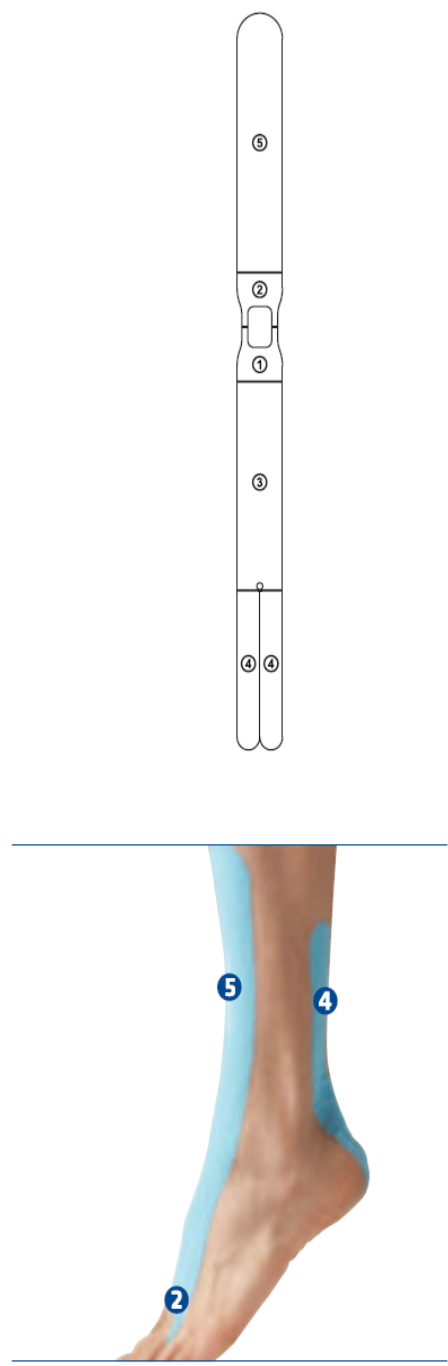

spider 8 tech. 